Cipango $\begin{aligned} & \text { Cipango } \\ & \text { Cahiers d'études japonaises }\end{aligned}$

$15 \mid 2008$

Guerre, colonialisme et commémoration

\title{
Taguchi Ukichi, un libéral opiniâtre de l'ère Meiji
}

Taguchi Ukichi, a Straightforward Liberal in the Meiji Era

\section{Pascal Hurth}

\section{(2) OpenEdition}

\section{Journals}

\section{Édition électronique}

URL : https://journals.openedition.org/cipango/111

DOI : 10.4000/cipango. 111

ISSN : 2260-7706

\section{Éditeur}

INALCO

\section{Édition imprimée}

Date de publication : 1 janvier 2008

Pagination : 129-174

ISBN : 978-2-85831-177-4

ISSN : $1164-5857$

\section{Référence électronique}

Pascal Hurth, «Taguchi Ukichi, un libéral opiniâtre de l'ère Meiji », Cipango [En ligne], 15 | 2008, mis en ligne le 11 novembre 2011, consulté le 30 juin 2021. URL : http://journals.openedition.org/cipango/ 111 ; DOI : https://doi.org/10.4000/cipango.111

Ce document a été généré automatiquement le 30 juin 2021.

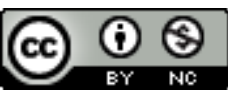

Cipango est mis à disposition selon les termes de la Licence Creative Commons Attribution - Pas d'Utilisation Commerciale 4.0 International. 


\title{
Taguchi Ukichi, un libéral opiniâtre de l'ère Meiji
}

Taguchi Ukichi, a Straightforward Liberal in the Meiji Era

\author{
Pascal Hurth
}

En respectueux hommage à Francine Hérail

1 L'œuvre de Taguchi Ukichi 田口枊吉, également connu sous le nom lettré de Teiken 鼎 軒 (1855-1905) - journaliste fondateur de la Tōkyō keizai zasshi 東京経済䧱誌 (Revue d'économie de Tōkyō), historien, homme d'affaires, homme politique, chantre conséquent et indéfectible du libéralisme à l'ère Meiji - est considérable. Personnage remarquable à maints égards, il fut quasiment isolé parmi ses contemporains, $\mathrm{y}$ compris parmi ceux qui se réclamaient du libéralisme. Les deux thèmes de cet article, qui porte aussi bien sur la politique extérieure que sur la politique intérieure, résument les idées de Taguchi :

- la défense du libre-échange, cristallisée dans la formule « République du commerce » (shōgyō no kyōwakoku 商業の共和国), inédite dans l'histoire du Japon;

- l'hostilité aux propriétaires fonciers qui mettent leurs terres en bail - les jinushi 地主 -, traduite par le refus d'une baisse de l'impôt foncier (Taguchi préconisa même sa hausse avec le temps !) et par une dénonciation de la situation des métayers ${ }^{1}$ (kosakunin 小作人).

2 Après avoir présenté rapidement la biographie de Taguchi, nous traiterons ces deux thèmes en exposant l'argumentation de l'auteur et son évolution, causes de son isolement, et en dégageant ses filiations intellectuelles.

3 Taguchi consacra l'essentiel de ses écrits aux problèmes économiques. En effet, de 1877 à 1905, près de la moitié de ses articles traitent directement des finances publiques, mais rares sont les textes qui présentent une continuité. Ils furent surtout de circonstance. Il ne s'agit donc pas d'une construction théorique, ni d'études systématiques, même si Taguchi publia trois ouvrages largement diffusés dans le public, dont le Jiyū kōeki Nihon keizai-ron 自由交易日本経済論 (L'économie japonaise et le libre-échange), en 1878. 
4 Malgré de talentueux représentants des deux premières générations de Meiji, comme Fukuzawa Yukichi (1834-1901) ou Taguchi Ukichi, le libéralisme, doctrine importée dès la fin du bakufu par le biais de traductions plus ou moins exactes, grâce à des économistes comme Kanda Takahira 神田孝平 (1830-1898), ne put s'imposer comme force politique et créer une base sociale large, à la différence de ce qui se produisit en Grande-Bretagne où il était né deux siècles plus tôt. Ses partisans les plus actifs, anciens guerriers de rang subalterne, ne furent qu'un petit groupe d'intellectuels et de publicistes, actifs à Tōkyō et sans relais réels en province. Incohérents, ils limitaient leur libéralisme au domaine politique et demeuraient farouchement protectionnistes et nationalistes dans le contexte des pressions des pays occidentaux et des traités inégaux. L'incompréhension de concepts inédits par l'ensemble de la population, le provincialisme de la vie politique, dominée pendant une partie de l'ère Meiji par les hommes de Chōshū et de Satsuma, et le manque de fermeté des dirigeants se réclamant de cette doctrine, souvent prompts aux compromis ${ }^{2}$, jouèrent aussi un rôle non négligeable dans leur échec. Dans ces conditions, le libéralisme, qui représentait une réelle rupture idéologique, ne put apparaître comme une politique crédible pour résoudre les problèmes que le Japon affrontait.

\section{Vie et œuvre de Taguchi}

5 Taguchi naquit à Edo, en $1855^{3}$, dans une famille de vassaux subalternes du bakufu depuis plus d'un siècle, occupant entre autres des fonctions dans la police de la ville. Son arrière-grand-père maternel, Satō Issai 佐藤一斎 (1772-1859), lettré confucéen, fut professeur à l'école fondée en 1630 par Hayashi Razan 林羅山 (1583-1657). En 1866, Taguchi succéda à son père comme guerrier et suivit les cours de cette école.

La famille Taguchi se réfugia à Yokohama lors des remous de la Restauration de Meiji. Ukichi, tout en travaillant, y apprit l'anglais avec David Thompson, missionnaire presbytérien américain ${ }^{4}$. Par la suite, il se convertit au protestantisme, dont il s'éloigna rapidement au nom de la «théologie libre » (jiyū shingaku 自由神学). En 1869, il entra à l'École militaire de Numazu (Numazu heigakkō 沼津兵学校), ouverte aux fils des anciens vassaux du shōgunat, puis il commença à étudier la médecine à l'hôpital de Shizuoka.

7 Il interrompit ses études en 1871, se fixa à Tōkyō et travailla au bureau des traductions du ministère des Finances, où il se consacra à l'économie politique et à l'histoire. Après la suppression du bureau des traductions, en 1874, il fut muté comme traducteur au bureau de la monnaie. En janvier 1879, il publia le premier numéro de la Tōkyō keizai zasshi. Durant cette période, il étudia surtout les doctrinaires libéraux, notamment Adam Smith ${ }^{5}$ (1723-1790), l'auteur de la Richesse des nations.

8 Taguchi fut aussi un disciple de l'École de Manchester, représentée par H. D. MacLeod, partisan du principe du laisser-faire ${ }^{6}$ (jiȳ hōnin 自由放任) et de l'anti-colonialisme utilitariste, fondés principalement sur l'argument économique d'absence de rentabilité, prôné par David Ricardo ${ }^{7}$ (1772-1823) ou Richard Cobden $^{8}$ (1804-1865). Il fut aussi un lecteur attentif de Frédéric Bastiat ${ }^{9}$ (1801-1850). En 1885-1887, il traduisit un ouvrage de MacLeod, The Principles of Economic Philosophy, publié en deux volumes sous le titre de Ma-shi keizai tetsugaku 麻氏経済哲学. 
9 Taguchi écrivit ses deux premiers ouvrages alors qu'il était encore très jeune : Nihon kaika shōshi 日本開化小史 (Brève histoire de la civilisation japonaise, 1877-1882), influencé entre autres par Guizot et les Anglais Herbert Spencer et Henry Thomas Buckle (1821-1862), tenants tous les deux d'une vision organiciste de l'histoire, et L'Economie japonaise et le libre-échange, déjà mentionné.

10 Taguchi intervint aussi en politique intérieure. Il adhéra à la société Ōmei-sha 塤鳴社 (Société de l'harmonie) ${ }^{10}$, fut éditorialiste au Jiyū shinbun 自由新聞 (Journal de la liberté), organe du Parti libéral, mais il démissionna pour adhérer au Parti constitutionnaliste de la réforme (Rikken kaishin-tō 立憲改進党, appelé aussi Kaishin-tō), fondé en avril 1882. Il fut élu au conseil d'arrondissement d'Ushigome à Tōkyō en juillet 1880, puis au conseil général de Tōkyō en décembre de la même année où il siégea jusqu'en juillet 1890.

11 En septembre 1894, il fut élu à la Chambre des représentants, où il siégea jusqu'à sa mort. Inébranlable dans ses convictions sur la politique fiscale, il quitta à deux reprises son groupe parlementaire, qui participait au gouvernement, pour siéger parmi les noninscrits ${ }^{11}$. Il intervint dans la défense des libertés publiques et critiqua la thèse de Katō Hiroyuki 加藤弘之 (1836-1916) sur le caractère prématuré de l'ouverture du Parlement, affirmant que ces droits étaient le support de la société pour une longue période. Toutefois il fut incapable de percevoir la nature même du problème social qui fit rapidement irruption à partir des années 30 de Meiji. Comme beaucoup de ses contemporains, il préconisa des rapports sociaux propres au Japon, fondés sur la «bienveillance » (onjō 温情), largement répandue selon lui chez les employeurs.

Il se lança dans les affaires en 1887 avec, entre autres, la création d'une ligne de chemin de fer dans les départements de Tochigi et Gunma afin de contribuer au développement de la sériciculture. Il fut aussi l'éditeur scientifique de recueils de documents historiques comme le Gunsho ruijū 群書類従 (Compilation de textes classés par genre) de Hanawa Hokiichi 塙保已一 (1746-1821) et le Kokushi taikei 国史大系 (Grande collection d'histoire nationale). Il créa la revue Shikai 史海 (L'Océan de l'histoire) et subit les critiques des adeptes du shintō et des études nationales. Mais l'essentiel de son activité concerna la création, puis le développement et la diffusion de son hebdomadaire, Tōkyō keizai zasshi, sur lequel nous reviendrons. Enfin, curieusement, à la différence de nombre de ses contemporains, Taguchi ne visita pas l'Occident. Ses seuls voyages outre-mer, officiels, eurent lieu au printemps 1890 à Guam et Palao, puis, à l'été 1904, au moment de la guerre russo-japonaise, dans le cadre d'une mission parlementaire sur le front de Mandchourie.

13 L'œuvre de Taguchi, considérable, débuta donc, en 1878 avec L'Économie japonaise et le libre-échange, fruit de trois années de recherches sur le libre-échange, la division du travail et l'échange de ses produits, sources de richesse dans l'esprit d'Adam Smith. Taguchi dénonce les entreprises d'État, jugées non rentables, et l'échec de la politique protectionniste pour trois raisons :

- elle est nuisible à l'intérêt du pays, même si elle profite à un secteur ${ }^{12}$;

- sur le marché intérieur, les taxes protectionnistes, créatrices d'un monopole concentrant le capital et le travail sur les marchandises protégées, sont préjudiciables à l'État ;

- le gouvernement n'a pas le droit d'octroyer le profit d'un individu à d'autres personnes, ce qui conduit Taguchi à rejeter la politique d'aide sociale aux anciens guerriers. 
individuelle, à interdire les privilèges injustifiés et à pourvoir aux seuls besoins de la société : l'enseignement et les travaux publics. Pour Taguchi, partisan d'un «État modeste ", le budget doit se limiter au strict minimum. Le Japon devait prendre la Grande-Bretagne, alors première puissance mondiale, pour modèle, sa prospérité économique reposant sur le libre-échange (qui, en vérité, fut progressif).

Or, à la même époque, le Japon était très loin du niveau de développement des puissances européennes, sa principale production industrielle exportée était le textile, avec la soie grège et les soieries, produits à faible valeur ajoutée. L'organisation de la production était encore archaïque, et la productivité, très faible. Cet écart de puissance ne gêna pas pour autant Taguchi en raison même des principes du libre-échange.

Après sa démission du ministère en octobre 1878 , Taguchi créa sa revue pour débattre de politique économique et populariser les principes du laisser-faire. Dans le manifeste du premier numéro, il en explique les raisons. À l'époque où il était fonctionnaire au ministère des Finances, un conseiller financier britannique, Alexander Shand, lui soutint que le Japon n'était pas encore assez riche pour lancer un périodique comme l'Economist. Taguchi releva le défi avec l'aide de Shibusawa Eiichi 渋沢栄一13 (1840-1931), fondateur de la banque Daiichi kokuritsu ginkō 第一国立銀行, qui finança la fusion de deux petits périodiques ${ }^{14}$, l'un spécialisé sur les questions bancaires, Ginkō zasshi 銀行雑誌 (Revue bancaire), édité en 1877 par le ministère des Finances, l'autre financier, Rizai shinpō 理財新報 (Revue financière), lancé en 1878 par Fukuchi Gen.ichirō ${ }^{15}$ 福地源一郎 (1841-1906), directeur du Tōkyō nichinichi shinbun 東京日日新 聞. Cette fusion permit à Taguchi de créer son journal, avec pour titre anglais explicite The Tōkyō Economist, le 29 janvier 1879. Shibusawa, par le biais de l'association Takuzenkai 択善会, le finança par une aide mensuelle de 100 yen et l'achat régulier de cinq cents numéros en échange de l'insertion d'informations sur la situation bancaire et la vie de la Takuzen-kai. Taguchi concluait le manifeste en affirmant que son journal devait être impartial et traiter des questions économiques au sens large, sans se limiter à la banque et à la finance. Il invitait ses lecteurs animés d'un esprit patriotique à s'abonner, démontrant ainsi au monde que le Japon était suffisamment riche pour lancer un périodique économique.

$\mathrm{Au}$ début, la revue comportait une quarantaine de pages, avec des articles économiques et politiques, puis des analyses sur le commerce et les banques, étayées par des statistiques, ainsi que des résumés d'articles parus dans d'autres journaux. Le prix était alors de 12 sen, un prix élevé pour l'époque, mais les ventes étaient satisfaisantes ${ }^{16}$. La périodicité initiale de 17 numéros par an la première année passa à 31 dès 1880, à 44 en 1881, et la revue devint hebdomadaire en 1882. Dans un premier temps, sa diffusion fut limitée au département de Tōkyō pour en dépasser rapidement le cadre étroit, et le tirage par numéro passa de 1469 en 1879 à 2628 en $1899^{17}$, cette faible diffusion étant avant tout liée à un lectorat extrêmement ciblé. La Tōkyō keizai zasshi, qui dura jusqu'au grand tremblement de terre de Tōkyō de septembre 1923, fit appel aux compétences d'universitaires, de hauts fonctionnaires, d'hommes politiques et de chefs d'entreprises ${ }^{18}$. Conformément à son libéralisme, elle accueillait dans ses colonnes des articles de partisans du protectionnisme afin de permettre à ses lecteurs de se forger leur propre opinion. économiques du Tōkai), d'Inukai Tsuyoshi 犬養毅 ${ }^{19}$ (1855-1932), fut lancé en août 1880, dans un contexte de polémiques. Malgré le soutien d'Iwasaki Yatarō 岩崎弥太郎 
(1834-1885), le fondateur de Mitsubishi, il ne dura que 76 numéros, s'arrêtant en octobre 1882, avec un tirage de 9686 exemplaires en 1881, dont 4060 dans le département de Tōky $\bar{o}^{20}$, pour 35 numéros dans l'année, soit une moyenne de 277 exemplaires par tirage.

Infatigable, Taguchi créa des sociétés de réflexion et d'étude, dont les objectifs étaient la traduction d'ouvrages occidentaux libéraux et la diffusion de ces idées. Outre sa revue, Taguchi, prenant pour modèle le Political Economy Club fondé à Londres par Thomas Tooke ${ }^{21}$, fonda le Séminaire d'économie politique (Keizai dankai 経済団会) en 1880, qu'il rebaptisa rapidement Société de Tōkyō de lectures économiques (Tōkyō keizaigaku kōshūkai 東京経済学講習会). Durant sept ans, la société se réunit régulièrement. Elle changea de nom en 1887, devenant l'Association de sciences économiques (Keizaigaku kyōkai 経済学協会). Ses membres étaient des hommes d'affaires, comme Shibusawa Eiichi et Masuda Takashi 益田孝 (1848-1938), un des fondateurs de Mitsui bussan ${ }^{22}$, des universitaires, des parlementaires et des journalistes. Shibusawa et Masuda y donnèrent des conférences. Cette société publia des traductions comme les Principles of Sociology de Herbert Spencer, et surtout La Richesse des nations ${ }^{23}$. La traduction de La Richesse des Nations par Ishikawa Eisaku 石川暎 作 et Saga Shōsaku 嵯峨正作 fut menée d'octobre 1882 à avril 1888 et publiée en douze fascicules sous le titre Fukoku-ron 富国論, à la grande satisfaction de Taguchi qui y voyait un outil permettant au peuple de comprendre l'économie, mais l'importance de sa diffusion est difficile à établir ${ }^{24}$. Durant sept ans, la société se réunit régulièrement.

Le libéralisme économique détermina la vision des relations internationales de Taguchi, qui demeura insensible au nationalisme et au militarisme. Cependant, certains historiens rappellent le patriotisme croissant d'un intellectuel qui défendit la loyauté envers l'État en raison de l'insuffisance de l'esprit d'ouverture des individus. Ce patriotisme n'altéra pas pour autant son attachement viscéral au libre-échange. Favorable à l'expansion commerciale et à l'émigration japonaise pacifique, il combattit avec la plus grande énergie le principe de la colonisation par la force ${ }^{25}$.

21 En fait, Taguchi reprit la distinction de Smith sur les colonies grecques libres et les colonies romaines assujetties ${ }^{26}$. Smith en effet renouvelle complètement la compréhension des bases de la puissance : l'étendue du marché devient la clef de la richesse, et non plus la dimension du territoire, car la division du travail ${ }^{27}$, moteur de la prospérité, est liée à la dimension de ce marché. La conclusion est triple :

- l'exploitation coloniale n'est bénéfique que pour une infime partie de la population;

- les charges supportées par la métropole du fait de la colonisation entraînent une déperdition d'hommes et de capitaux qui constitue une cause réelle d'affaiblissement plutôt qu'un facteur de puissance ;

- l'intérêt général, du colonisateur comme du colonisé, commande la rupture des liens de dépendance, qui doivent être remplacés par des accords librement consentis entre les puissances souveraines.

Après la guerre sino-japonaise de 1894-1895, Taguchi demanda l'application à Taïwan des principes gouvernant les colonies grecques libres et il voulut combattre les monopoles institués dans l'île au profit du Japon ${ }^{28}$.

Hostile à l'annexion de la Corée, il polémiqua avec ceux qui y voyaient un moyen efficace d'arrêter l'avance russe vers le sud. En juillet 1900, dans l'article "Quelles exigences après le rétablissement de l'ordre en Chine ${ }^{29}$ ?» (Shinkoku jihen seitei-go no yōkyū ikan 清国事変靖定後の要求如何), il écrit que cette annexion aurait pour seul 
résultat d'attiser l'animosité des Coréens à l'égard du Japon et qu'elle n'a aucun sens sur le plan stratégique. Pendant la guerre russo-japonaise, en juin 1904, il publie un article au titre explicite: «Respectons l'indépendance de la Corée ${ }^{30 ! " ~(K a n k o k u ~ n o ~}$ dokuritsu o sonchō subeshi 韓国の独立を尊重すべし). Il y défend le principe de la réciprocité dans les échanges, notamment pour l'achat de terres, et met en garde le gouvernement contre l'envoi de troupes en dépit d'un refus coréen : il se déshonorerait aux yeux du monde.

Cependant Taguchi omet de mentionner les conditions de la signature du traité d'amitié nippo-coréen (Nitchō shūkō jōki 日朝修好条規) de 1876 $6^{31}$, dit aussi Traité de Kanghwa (Kōka jōyaku 江華条約), ainsi que l'hégémonie commerciale exercée sur la Corée depuis les années $1890^{32}$.

À la veille et au début de la guerre sino-japonaise, Taguchi plaça ses espoirs dans le gouvernement coréen pour qu'il entreprenne de profondes réformes inspirées de la Restauration de Meiji. Il prôna notamment des mesures favorables aux intérêts japonais, destinées à contrer la Russie. Lors de la guerre de 1904-1905, il rejeta la responsabilité des hostilités sur cette dernière, incriminant son mépris des traités, et il soutint la politique de guerre. C'est dans ce contexte, en août 1904, qu'il défendit une alliance politique et économique avec l'Angleterre et les États-Unis, jugeant indispensable d'empêcher de nouveaux déploiements russes.

La publication de ses œuvres complètes eut lieu en 1927-1929 sous le titre Teiken Taguchi Ukichi zenshū 鼎軒田口卯吉全集. Chacun de leurs huit volumes était présenté par un intellectuel de renom, libéral ou de gauche :

1. Histoire présenté par Kuroita Katsumi 黒板勝美 (1874-1946), fondateur du Centre de compilation des documents historiques (Shiryō hensan-jo 史料編纂所) et ancien collaborateur de Taguchi avec lequel il participa à la publication du Kokushi taikei et du Gunsho ruijū.

2. Civilisation et société présenté par Fukuda Tokuzō 福田徳三 (1874-1930), économiste et fondateur de la Société de l'aube (Reimei-kai 黎明会, 1918-1920), centre intellectuel pour la défense de la démocratie, et par Yoshino Sakuzō 吉野作造 (1878-1933), juriste chrétien, hostile à l'expansion sur le continent, un des fondateurs du Parti socialiste populaire (Shakai taishū-tō 社会大衆党).

3. Théorie et polémiques économiques présenté par Kawakami Hajime 河上肇 (1879-1946), économiste marxiste, qui adhéra au Parti communiste japonais en 1932.

4. Politique économique présenté par Kushida Tamizō 串田民蔵 (1885-1934), économiste marxiste, membre du courant critique de la ligne du Parti communiste (Rōnō-ha 労農派), élève de Kawakami Hajime.

5. Politique présenté par Yoshino Sakuzō.

6-7. Finances publiques et privées présenté par Ōuchi Hyōbei 大内兵衛 (1888-1980), autre membre du Rōnō-ha.

8. Essais présenté par Hasegawa Nyozekan 長谷川如是閉 (1875-1969), penseur libéral influencé, entre autres, par Mill et Herbert Spencer.

En 1990, la maison d'édition Yoshikawa kōbunkan réédita en fac-similé les œuvres complètes de Taguchi. 


\section{La « République du commerce »}

28 "République du commerce»: la force de la formule frappe encore aujourd'hui les historiens par son aspect iconoclaste, elle est la négation de facto d'une part de la souveraineté nationale, représentée par le Parlement et surtout l'empereur. Elle cristallise la pensée de Taguchi sur le libre-échange, perçu comme une source de prospérité au contraire du protectionnisme et des ingérences de l'État (barrières douanières incluses). Mais l'optimisme de Taguchi trouve ses limites dans le contexte mondial de l'époque qui voit le retour progressif du protectionnisme en Europe.

En vérité, le mot «République », dont l'étymologie latine res publica (chose publique) est liée à l'intérêt général, revêt une grande ambiguïté sémantique. Sa connotation évolua dans le temps, de Platon, Cicéron, Thomas More et Jean Bodin, à la Révolution française. Montesquieu, dans De l'Esprit des lois, définit le gouvernement républicain comme celui où le peuple en corps, ou seulement une partie du peuple, a la souveraine puissance, tandis que Rousseau, dans le Contrat social, la définit comme tout Etat régi par des lois (pour lui, tout gouvernement légitime est donc républicain). Les événements de 1792 aboutissent à la connotation contemporaine de "République républicaine ${ }^{33}$ ».

Quant au mot chinois gonghe 共和 (japonais kyōwa) - «commune harmonie »-, il apparaît dans les Mémoires historiques (Shiji 史記) de Sima Qian (145 ?-86?) pour désigner la régence exercée par deux conseillers après la fuite du roi Li (878-828) dans la ville de $\mathrm{Zhi}^{34}$.

31 Par ailleurs, Taguchi ne développa pas son projet de gouvernement mondial du commerce; ou, plus exactement, ses œuvres complètes ne contiennent aucun article sur un tel projet d'organisation et de réglementation du commerce international, ou même régional ou bilatéral, notamment avec la Corée et la Chine. La formule relève donc moins d'une proposition concrète et détaillée que d'une formule de rhétorique ou d'un vœu pieux.

En vérité, Taguchi ne semble l'avoir employée que deux fois en plus de vingt-cinq ans. La première en mars 1883 dans un article intitulé « Le système colonial » (Shokumin-sei 殖民制), sans aucun développement ${ }^{35}$. La seconde fois, dans un texte publié en janvier 1887, repris dans un recueil d'articles ${ }^{36}$ publié en avril 1890 sous le titre Zoku keizai-saku 続経済策 (Politique économique, suite).

Il prend le terme "République " sans expliquer son étymologie latine, dans le sens antérieur à la Révolution française et, à la différence d'Ozaki Yukio 尾崎行雄 ${ }^{37}$, il ne préconise pas ce régime politique pour le Japon. En fait, l'expression de Taguchi peut être aussi traduite par "gouvernement du commerce». Dans le texte publié en 1887, après un long développement sur l'histoire du monde, il écrit :

Vous devez savoir que, du point de vue économique, souverains et Premiers ministres ne sont que des préfets et des chefs d'arrondissement de haut rang, que leurs territoires ne sont que des départements et que la population mondiale n'est que la population d'un immense pays, la République du commerce. On pourrait envisager que les souverains et les présidents de la République se réunissent pour délibérer dans un gouvernement d'union. Les chefs d'État formeraient la Chambre haute, le peuple la Chambre basse; la politique nationale serait abolie, remplacée par une administration provinciale directe. À partir de demain, les noms des pays comme Angleterre, France ou autres seraient sans rapport avec leur peuple, comme c'est le cas aujourd'hui chez nous où les noms des provinces de Musashi ou de Sagami n'ont que peu de rapports avec la réalité. Actuellement les peuples se battent pour ces noms et 
gaspillent leurs vies et leurs biens pour des choses sans grande valeur. Si l'on tentait d'éradiquer cette distinction politique, croyez-vous que les peuples en souffriraient? [...] L'économie de notre pays a connu un formidable développement avec la chute de la féodalité, et le Zollverein ${ }^{38}$ a permis au commerce allemand d'accomplir d'énormes progrès. Quand on y réfléchit, la distinction politique est seulement artificielle, elle est sans rapport avec les véritables intérêts des peuples. Non seulement, elle n'a aucun lien réel avec ceux-ci, mais, au contraire, elle les bride. Le développement suffisant du commerce mondial ne permettrait-il pas la fabrication de produits plus adaptés aux besoins des peuples de chaque pays? [...] Dans le dispositif mondial des cinq continents, le Japon n'est qu'une pièce du jeu de go. Les départements ne doivent pas contingenter le commerce. [...] Si on faisait en sorte que les hommes politiques ne puissent pas intervenir dans le commerce, comme les préfets des départements ne peuvent pas intervenir dans le commerce extérieur, le commerce en profiterait, ce qui permettrait la prospérité, et le morcellement politique serait comme aboli de facto. ${ }^{39}$

Taguchi poursuit en expliquant la prospérité de Londres et de Shanghai (présentée comme un exemple à suivre, plus proche géographiquement et historiquement d'un Japon qui doit développer ses échanges avec cette ville). Les ports de Tōkyō et de Nagasaki doivent assurer le développement des exportations en Chine, alors que les Allemands et les Russes s'y implantent. Tōkyō doit être le marché central de la zone économique Pacifique, les ports japonais devraient ravir un jour prochain le rôle de Shanghai et de Hong-Kong dans le commerce régional ${ }^{40}$. Toutefois, avec le temps, l'admiration pour la Chine se transforma peu à peu en mésestime, surtout après la défaite de celle-ci en 1895.

Taguchi envisage alors la «République du commerce » du point de vue du profit du Japon. Il rêve d'une pax japanica ${ }^{41}$, fondée sur un État commerçant relais dans le Pacifique. Par la suite, consécutivement au déclin de la Chine des Qing ${ }^{42}$, pourrait s'édifier un ordre nouveau en Extrême-Orient. Dans cette zone, le Japon doit s'affirmer comme puissance commerciale, et non comme puissance militaire, opinion d'ailleurs partagée à la même époque par Fukuzawa.

Cette argumentation conduit Taguchi à dénoncer les ingérences de l'État :

Les interventions politiques ne sont-elles pas éminemment préjudiciables au commerce? De même que des alcools fins et des mets délicats récompensent un travail de longue haleine, un bain et de la bouillie de riz permettent de récupérer de la fatigue, et les commerçants qui ont franchi des milliers de kilomètres de mers démontées aspirent à ne pas être gênés par les interventions politiques. Si la politique anglaise n'est pas encore tout à fait dégagée de tout interventionnisme, elle n'en est pas loin. N'est-il pas évident que les grands principes $d u$ commerce international ont apporté la prospérité?

Au-delà de cette formule de "République du commerce » ou de la comparaison du Japon avec une simple et banale pièce de jeu de go, qui ne pouvaient manquer d'offusquer, Taguchi tient le libre-échange pour une vérité scientifique, qui ne peut que fortifier son pays. Il serait aussi vain selon lui de restreindre la circulation des marchandises dans le monde que de vouloir limiter la circulation des éléments naturels tels que l'air ou les courants marins. Taguchi, qui avait étudié la médecine, recourt à des métaphores médicales pour expliquer les échanges de marchandises et de monnaie dans le commerce international ${ }^{43}$; il emploie, entre autres, les mots "cœur» et " poumon » pour désigner les positions centrales qui amassent des profits. Il emploie toujours un ton rationaliste et pragmatique, comme le médecin prescrivant un remède concret à son patient. 
38 Il passe ensuite de l'analogie scientifique à l'argumentation politique, posant le problème des rapports entre le politique et l'économique: le marché prime sur les décisions des hommes politiques en raison de sa puissance bénéfique et irrésistible. Dès la publication de Jiyu kōeki Nihon keizai-ron, Taguchi affirme que les conflits entre grandes puissances sont avant tout du même ordre que les rapports politiques. Les rapports économiques, eux, sont d'un autre ordre: ils engendrent des rapports de dépendance réciproques entre États. Taguchi, sans nier l'existence de pays, de nationalités, ni des guerres ${ }^{44}$, soutient que l'économie ne connaît pas de frontières (dont le tracé, du point de vue de l'économie et du commerce, n'a pas grand sens pour les hommes et les choses). Il conclut donc que le monde est une communauté économique, une République du commerce.

Pour Taguchi, l'économie ne connaît donc aucune différence fondamentale entre l'intérieur et l'extérieur; elle doit fonctionner selon les mécanismes du libre-échange, d'autant que la richesse d'un pays ne peut s'acquérir que par la monnaie et le commerce. Cet ordre est fondé sur le seul critère du profit, seule source de richesse (contrairement à l'impôt), et l'État doit se garder de toute ingérence dans le commerce. En 1898, dans 《De la politique étrangère » (Taigai kokuze 対外国是), il écrit que la puissance d'un pays se mesure à sa prospérité et non à sa superficie ${ }^{45}$. En conséquence, l'important pour le Japon n'est pas l'expansion territoriale, mais le progrès de son commerce. Le modèle est l'Angleterre, mais Taguchi ignore que, confrontée à de sérieuses difficultés économiques d'ordre structurel, celle-ci revient alors peu à peu à une politique protectionniste. Il reconnait que cette politique peut provoquer des crises dans certains secteurs, mais il estime qu'elles sont compensées par des profits permettant le maintien d'un équilibre, ce qui le conduit à préconiser la division internationale du travail. Il ajoute que la production des biens est indépendante des régimes politiques, et il cite l'exemple de la France et de l'Italie, toutes deux productrices de vin. La première est une République, la seconde une monarchie. Par ailleurs, il étaye cet article avec de nombreux exemples tirés de l'histoire mondiale, qui attestent de sa vaste culture historique.

La solution réside dans la fin des entraves que les gouvernants imposent au commerce extérieur, et donc dans la suppression des droits de douane et la liberté accordée au commerce extérieur. Alors les ports japonais pourront commercer non seulement avec la Chine, mais avec le monde entier. Les gouvernants ne doivent pas s'illusionner sur les phénomènes politiques, mais être conscients de la réalité de la République du commerce. Tōkyō deviendra alors une grande place économique, à la prospérité inégalée. Cependant, pragmatique, Taguchi précise, en 1889 que, dans un contexte national où la pensée économique en est encore à un stade infantile, il craint que son idée ne soit inacceptable. Par conséquent, il se limite pour l'instant à une diminution substantielle des taxes. Le gouvernement s'est déjà attelé à cette tâche avec l'abrogation partielle de la taxe sur les exportations ${ }^{46}$, l'année précédente, mais de nombreux produits y sont encore soumis. Or il n'y a encore qu'un ou deux pays qui lèvent cette taxe, dont le Brésil. Cette taxe doit donc être abolie ${ }^{47}$. Cette politique est le fer de lance de la richesse et le Japon doit faire un pas en avant dans cette direction.

41 Une autre conséquence de cette "République du commerce ", liée à l'ouverture totale de l'économie japonaise et à la modernisation du pays, est le consentement total de Taguchi à la liberté de résidence des étrangers au Japon (naichi zakkyo 内地雑居), qui n'entra en vigueur qu'en 1899 après le début de la révision des traités inégaux ${ }^{48}$. Dans le 
Zoku keizai-saku, il vante le mérite de la politique de circulation des élites étrangères pratiquée à Londres.

Par ailleurs, Taguchi martèle constamment son opposition à l'expansionnisme militaire, aux guerres dilapidatrices des richesses et des biens, qui ne peuvent que provoquer un sourire sardonique, car il ne peut y avoir de véritables vainqueurs. À l'instar du libéralisme européen, le pacifisme de Taguchi est moins idéologique ou émotionnel que pragmatique.

43 Taguchi explique que les guerres conduites au nom des pays - folies inévitables et incompréhensibles - détruisent les vies et les richesses ${ }^{49}$. Par conséquent, la " puissance commerciale » (shōgyō no chikara 商業の力) est la seule et unique clef d'accès d'un pays à l'indépendance. L'Angleterre, île isolée, en administre la preuve évidente, et sa prospérité repose sur le libre-échange. La sage politique britannique réside « dans la domination des régions productrices par les grandes villes et la maitrise des mers ${ }^{50}$ » (Taguchi oublie néanmoins de préciser comment s'est construit l'empire britannique). Le commerce rend inutile l'emploi des armes, uniquement réservées à la défense du pays. Taguchi conclut que les peuples du monde sont des « peuples libres de la République du commerce» (shōgyō kyōwakoku no jiyūmin 商業共和国の自由民). Aussi, quelle que soit l'importance absolue et relative de la population japonaise dans le monde, elle ne peut subir ni pertes ni profits, car elle se trouve sur le même pied d'égalité que les autres peuples.

En vérité, en 1879 Taguchi constate que les traités conclus avec les puissances étrangères privent le Japon de toute souveraineté douanière, en faisant un "pays tributaire ", mais il ajoute que le gouvernement de Meiji se trouve dans une situation de dépendance, inconnue à l'époque du bakufu, et qu'il doit s'insérer dans un ordre

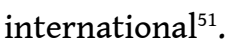

45 Mais Taguchi est aussi préoccupé par l'expansion russe. Il faut lui barrer la route du sud, ce qui devrait constituer la base de la paix en Extrême-Orient. Taguchi proposait de faire de la Mandchourie une zone-tampon entre l'Extrême-Orient russe, la Chine et la Corée. Cette hantise de la menace russe le conduit à modifier son évaluation du rôle militaire du Japon en Extrême-Orient, où il doit assurer le maintien de la paix, ce qui implique la constitution d'une puissance militaire.

Taguchi appelle ainsi à un dépassement de l'État-nation, tout au moins dans le commerce international. Pierre Rosanvallon, dans Le Libéralisme économique, pose le problème des rapports entre le marché et l'État-nation - «forme particulière d'investissement de l'espace par le politique ", qui se construit par la production d'un territoire, « espace de souveraineté politique homogène et clairement délimité ${ }^{52}$ ». Or le pouvoir centralisé est récent au Japon, et les particularismes locaux y étaient encore très vivaces, en raison de l'isolement d'un grand nombre de régions, dû, entre autres, au mauvais état des routes et au faible nombre de kilomètres de chemin de fer (le désenclavement se produira seulement à partir des années 1890). Le gouvernement combat des particularismes locaux par «la rhétorique de l'unité nationale constamment brandie comme un talisman contre les conflits d'intérêts locaux ${ }^{53}$ ». À la récente unification en cours du marché intérieur, réalisée, entre autres, par la levée des barrières et octrois, Taguchi voulait ajouter celles du marché international.

L'opportunité des propositions de Taguchi est jugée le plus souvent inadéquate, et nombre d'historiens pensent que les analyses de l'économiste Friedrich List (1789-1846), artisan de l'Union douanière allemande (Zollverein), répondaient davantage 
aux besoins du Japon de Meiji. En effet, List dans son Système national d'économie politique, publié en 1840, préconisait un protectionnisme temporaire pour les industries naissantes. Ses idées furent en vogue dans la seconde moitié de l'ère Meiji.

\section{Les sources} japonaise et occidentale. À ses débuts, il se réfère encore aux philosophes classiques chinois pour appuyer sa description du laisser-faire. Les sages de la Chine ancienne érigeaient le non-dirigisme en principe de gouvernement. Le concept de dairi 大理 selon $\mathrm{Zhu} \mathrm{Xi,} \mathrm{unique} \mathrm{et} \mathrm{ultime} \mathrm{principe} \mathrm{qui} \mathrm{gouverne} \mathrm{l'univers} \mathrm{entier,} \mathrm{aida} \mathrm{sans} \mathrm{doute}$ Taguchi à accepter la doctrine du laisser-faire. Par une analyse organiciste, ce dernier affirme que le monde économique possède naturellement son propre "principe fondamental », que la richesse et la force ne peuvent être obtenues par un dirigisme artificiel, et que le libre-échange est une matérialisation explicite dudit principe. Les divers éléments constitutifs du monde économique ne sont agencés dans un ordre harmonieux que s'ils relèvent de la doctrine du laisser-faire.

La filiation avec la pensée économique de l'époque d'Edo est complexe. Les économistes partisans du commerce extérieur ne pouvaient sortir du cadre du monopole du bakufu et des fiefs. Honda Toshiaki en esquisse les principes sans pour autant récuser le contrôle de l'État ${ }^{54}$. Dans son Traité des échanges extérieurs (Kaikoku kōeki-ron 開国交易 論), publié en 1801, il n'hésite pas à comparer les enjeux du commerce extérieur à ceux d'une campagne militaire, et il souligne la nécessité de construire des bateaux capables de rivaliser avec les navires étrangers. La prospérité ne se conçoit que dans le cadre des échanges internationaux, mais sous le contrôle du gouvernement, par crainte de la cupidité des marchands.

Kaiho Seiryō 海保青陵 (1755-1817) soutenait pour sa part la libéralisation des échanges entre fiefs, par la levée des barrières commerciales, mais sous le contrôle desdits fiefs. Il considérait les activités commerciales capitalistes comme naturelles et nécessaires, ainsi que comme sources de richesse. Il dénonçait l'augmentation de la redevance seigneuriale pour accroître le montant des recettes, car elle attise les conflits entre gouvernants et gouvernés.

51 Satō Nobutsuna 佐藤信綱 (1769-1850), dans sa Politique de défense côtière (Kaibō-saku 海 防策), expliquait que l'Angleterre, nonobstant ses ressources limitées, était devenue riche et puissante grâce à son commerce extérieur ${ }^{55}$. À l'instar de Honda, il préconisait le contrôle du bakufu, ajoutant que l'absence d'un tel commerce extérieur était néfaste à la population, et il dressait même un tableau apocalyptique d'un pays qui en serait dépourvu ${ }^{56}$. Cette opinion, cependant, rencontrait aussi de farouches détracteurs ${ }^{57}$.

D'autres économistes développent des thèses plus hardies. Ainsi, Yamagata Bantō 山片 蟠桃 (1748-1821), riche négociant en riz d'ōsaka, défendait le principe de la liberté du commerce et des profits. En conséquence, il pensait également que les prix doivent être fixés par la loi de l'offre et de la demande. De même, Ishida Baigan 石田梅岩 (1685-1744) valorisait la notion de profit et affirmait l'utilité générale des échanges et du commerce. Dans son Dialogue sur la ville et la campagne, publié en 1739, Baigan parle de l'enrichissement comme d'un devoir moral, conforme à la "voie des marchands » (shōnin no michi).

Cipango, 15 | 2008 

invisible " d'Adam Smith, un mécanisme invisible de régulation qui harmonise et coordonne les intérêts individuel ${ }^{58}$. Pour Smith en effet, l'individu, motivé par son propre gain, "est conduit par une main invisible à remplir une fin qui n'entre nullement dans ses intentions " et il travaille plus efficacement pour l'intérêt de la société "que s'il avait réellement pour but d'y travailler ${ }^{59}$ ", ce qui rend possible la création et la distribution des richesses pour le bénéfice de tous, ou tout au moins du plus grand nombre ${ }^{60}$, et ce qui permet une régulation de l'ordre social et du bien public par l'intérêt personnel.

Taguchi reprend aussi l'analyse de Smith sur le marché mondial :

Si toutes les nations venaient à suivre le noble système de la liberté des exportations et des importations, les différents États entre lesquels se partage un grand continent ressembleraient à cet égard aux différentes provinces d'un grand empire.

Smith voit aussi dans ce système le meilleur moyen pour se défendre contre les inconvénients de la cherté et les risques de famine. À une époque où les barrières politiques et douanières sont fortes, il préconise un marché économique mondial ignorant les frontières des États-nations ${ }^{61}$. Il explique en outre :

Un marchand [...] n'est pas nécessairement citoyen d'un pays particulier. Il lui est, en grande partie, indifférent en quel lieu il tienne son commerce, et il ne faut que le plus léger dégoût pour qu'il se décide à emporter son capital d'un pays à l'autre, et avec lui toute l'industrie que ce capital mettait en activité. ${ }^{62}$

Selon Pierre Rosanvallon ${ }^{63}$, « le fantasme universaliste, autrefois vécu dans l'image de la chrétienté, retrouve avec Smith un nouveau visage et un nouvel élan sur un mode radicalement laïcisé ", qui annonce donc la déterritorialisation de l'économie et l'effacement de la figure transitoire de l'État-nation. Rosanvallon considère Smith comme le premier internationaliste conséquent, dans un monde dont les premiers citoyens sont des marchands apatrides.

Par ailleurs, l'opposition du commerce et de la guerre se trouve également chez Montesquieu qui, dans De l'esprit des lois, dès 1748, affirme que le commerce apporte la paix et unit les nations. Il influença Adam Smith et les autres intellectuels écossais du XVIII $^{\mathrm{e}}$ siècle $^{64}$.

58 Taguchi est encore fidèle à Adam Smith sur le problème de la sécurité et de la défense des intérêts nationaux ${ }^{65}$. Il défend le principe d'une force militaire chargée de la protection de la société contre la violence et l'invasion d'autres sociétés indépendantes, tout en insistant sur la diversité des conditions historiques. Il souligne, en 1776, que les progrès techniques ont provoqué un renchérissement des coûts de l'armement et de l'entretien du soldat, ce qui ne peut que justifier le principe d'une armée strictement vouée à la défense du territoire : la répartition des dépenses de défense doit se faire sur la base d'un critère d'équité sociale ${ }^{66}$. Un siècle plus tard, Taguchi ne pouvait qu'acquiescer à ces propos, a fortiori dans un Japon pauvre, alors que l'Angleterre de Smith était déjà puissante.

59 Taguchi est aussi redevable à l'École de Manchester et à MacLeod, défenseur inconditionnel de la propriété privée, pour qui la demande est l'unique source de la valeur, et viscéralement hostile au protectionnisme et au socialisme, entraves à la liberté des échanges, source de prospérité. En raison des progrès de l'économie politique, l'École de Manchester, à la différence de Smith ou de Ricardo, ajoutait aux biens corporels les biens incorporels, comme les effets de commerce, les titres, les

Cipango, 15 | 2008 
droits d'édition ou les brevets d'invention. Cependant, aucun de ces auteurs ne semble avoir utilisé l'expression "République du commerce », dont Taguchi semble bien être le père.

60 La singularité de cet auteur s'étendit aussi à la question sensible de la propriété et de la fiscalité foncières, dans un Japon encore très rural.

\section{L'hostilité aux propriétaires fonciers}

61 Taguchi fut un des rares publicistes et hommes politiques non membres d'un gouvernement à défendre l'impôt foncier, puis à préconiser sa hausse dans les années 1890. Il tenait cet impôt pour équitable, contrairement à d'autres dont il demandait l'abrogation parce qu'il les jugeait injustes. Il consacra de nombreux articles à cette question ${ }^{67}$. Dans «De l'impôt » (Sozei-ron 租税論 ${ }^{68}$ ), publié en 1880, il affirme que, en raison de l'inefficacité des autres taxes, il n'y a pas de meilleur impôt que l'impôt foncier (zenryō naru sozei wa chiso ni gotoku nashi 善良なる租税は地租に如くなし). Il soutint que la hausse de cet impôt est acquittée non par le propriétaire, mais par le consommateur, et manifesta ainsi une plus grande capacité d'analyse que ses contemporains (en particulier que les militants du mouvement pour la liberté et les droits du peuple). Il s'opposa aussi constamment à toute révision du prix des terres. Sa théorie sur la fiscalité foncière se situe dans la droite ligne de l'orthodoxie libérale de Ricardo, ce qui le conduisit à manifester constamment une très vive animosité à l'égard des propriétaires fonciers et du système du métayage. Cette animosité s'élargit aussi au plan politique puisque Taguchi jugea excessif le poids desdits propriétaires dans les assemblées élues, qu'elles fussent locales ou nationales. Cette véhémence à leur égard devint viscérale vers 1900, comme l'atteste une conférence prononcée en février 1903, dont le ton relève moins de l'analyse que de l'invective ${ }^{69}$.

L'originalité des arguments tient au contexte d'un Japon encore très rural, qui démarre sa révolution industrielle, ce qui se traduit par une représentation écrasante des propriétaires fonciers au Parlement. L'animosité de Taguchi est aussi liée à une critique systématique de la fiscalité des conseils généraux. Il juge en effet inéquitables les impôts départementaux (chihō-zei 地方税), notamment la taxe d'habitation (kosū-wari 户数割) et la patente (eigyo-zei 営業税). En outre, cette hostilité s'étend à la politique agricole protectionniste. Ainsi, en 1897, il réclame la suppression de la Banque de l'agriculture et de l'industrie (Nōkō ginkō 農工銀行), considérée comme une dépense inutile.

\section{L'impôt foncier}

À l'époque d'Edo, l'impôt seigneurial (nengu 年貢) acquitté par la commune était fondé sur la valeur des biens produits par celle-ci (kokudaka 石高), estimée par rapport à une production de riz exprimée en koku $(1 k o k u=180 \mathrm{l})$. Le taux effectif est difficile à mesurer, mais au tout début de l'ère Meiji, il est évalué entre le quart et le tiers de la récolte. Le gouvernement, confronté au financement des dépenses de modernisation et hostile à tout emprunt extérieur, élabora pendant cinq ans une réforme de cette fiscalité. Après une période transitoire, il maintint le système du kokudaka et instaura la 
liberté du commerce des terres, concrétisée par des titres de propriété indiquant la valeur vénale du terrain.

En 1873, il promulgua une réforme de l'impôt foncier en rupture avec la pratique de l'époque d'Edo. Désormais, l'impôt porterait sur la valeur foncière, liée aux conditions d'exploitation, et non sur le revenu, source de recettes plus aléatoires (et jusqu'en 1890, l'impôt foncier représenta plus de la moitié des recettes fiscales). Ici et là, les modalités d'application provoquèrent des révoltes paysannes d'ampleur inégale. Soucieux de maintenir le niveau des recettes provenant de cet impôt, tant que d'autres financements ne seraient pas dégagés, le gouvernement modifia à plusieurs reprises l'ordonnance de 1873 sur la réforme de l'impôt foncier, ramené à 2,5\% de la valeur foncière depuis 1877 , celle-ci étant calculée sur la base de la valeur de la récolte et du capital-terre, c'est-à-dire de l'investissement financier et humain (rishi 利子). En 1880, le gouvernement ajourna sa révision; puis, de 1884 à 1889, il la modifia sur plusieurs points, avec pour objectif le maintien des recettes tirées de cet impôt.

$\mathrm{Si}$, avec le temps, le pourcentage de ces recettes diminua, la guerre avec la Chine obéra lourdement les finances publiques. Le gouvernement s'engagea dans une politique de hausse des crédits d'armement, de financement des investissements à Taïwan (arraché à la Chine) et d'assainissement financier. Après maintes péripéties, la Chambre des représentants passa un compromis en trois points avec le Premier ministre Yamagata Aritomo 山県有朋 (1838-1922) en décembre 1898 :

- Engagement formel de remédier au déséquilibre régional du prix des terres, critère de l'évaluation de l'impôt foncier.

- Promesse de ramener la hausse de l'impôt foncier, décidée par le cabinet d'Itō Hirobumi en janvier 1898, de $60 \%$ à $32 \%$ (soit 3,3 \% de la valeur de la terre).

- Limitation de l'augmentation aux cinq prochaines années, de 1899 à 1905.

Le premier cabinet Katsura (1902-1903) tenta de prolonger la période de la hausse, mais l'opposition de la Rikken Seiyūkai 立憲政友会 ${ }^{70}$ et d'autres partis l'en empêcha. Le taux fut donc ramené à l'ancien niveau de $2,5 \%$ en 1904. Toutefois la guerre avec la Russie éclata en février 1904, et le gouvernement, en avril et en décembre de la même année, fit adopter par les deux chambres une loi fiscale exceptionnelle qui fit passer le montant de l'impôt foncier à $7,2 \%$ de la valeur de la terre.

Taguchi lie étroitement les arguments techniques, moraux et politiques, qu'il situe dans une perspective libérale, à la vision d'un Japon urbain voué à l'industrie et aux services. L'impôt foncier - impôt national vanté pour sa justice - est constamment opposé à la patente et à la taxe d'habitation, impôts relevant des conseils généraux. Cette hostilité s'accrut au fur et à mesure du gonflement des recettes tirées de la patente, pratiquement triplées de 1879 à $1888^{71}$. Taguchi demanda leur abrogation, ainsi que celle des taxes diverses relevant de la même catégorie.

Toutefois Taguchi fait preuve de souplesse selon la conjoncture. Il se soucie moins du taux de l'impôt que de la charge réelle qu'il représente pour les paysans ${ }^{72}$. En 1880, époque d'inflation, il soutient, au nom de l'équité, le décret d'ajournement d'une révision de l'impôt foncier, car le prix élevé du riz, pris pour critère, aurait à terme pénalisé les paysans ${ }^{73}$. Dans un autre texte de mai $1889^{74}$, il réitère cette position pour le prix du riz à Tōkyō qui, en 1876, était de 5,20 yen. Taguchi, malgré son opposition de principe, demande alors une baisse exceptionnelle de l'impôt foncier, compensée par la diminution du traitement des fonctionnaires et d'autres économies budgétaires. 


\section{Arguments techniques} non son métayer ${ }^{77}$. Comme la plupart des autres impôts, il est répercuté sur le consommateur. Par ailleurs, dans un article publié le 24 novembre 1883, lors de la crise déflationniste du début des années 1880 : «Aux paysans » (Nōka ni tsugu 農家に告ぐ78), Taguchi explique que les deux causes principales des variations du prix du riz sont conjoncturelles : le volume de la masse monétaire en circulation et celui des récoltes, en d'autres termes, il s'agit d'un problème de marché, d'offre et de demande. Les deux causes sont liées. Si une récolte abondante profite au paysan, ses effets peuvent être inverses en cas d'une altération de la monnaie qui renchérit les coûts de production et provoque ainsi une vente à bas prix. Pour pallier les difficultés d'acquittement de cet impôt, Taguchi préconise un aménagement technique des tranches de paiement tenant compte des conditions climatiques ${ }^{79}$.

71 En octobre 1880, dans l'article « Sozei-ron », il ajoute que l'impôt foncier, direct et payé par tous, est l'impôt le plus égalitaire, car il pèse sur tout terrain d'habitation, nonobstant la profession exercée. Il comporte en outre des catégories et des tranches ${ }^{80}$, au contraire des autres impôts qui ont un taux uniforme. On retrouve ici le thème de l'équité fiscale.

Par ailleurs, Taguchi explique dans le même article que l'impôt foncier a le coût de prélèvement le plus faible, car, contrairement à la taxe sur les alcools, il ne nécessite pas l'envoi tout au long de l'année de contrôleurs du volume de production. La décision est prise par la consultation de registres fonciers. Pour lui, la taxe sur les alcools est la plus insupportable, comme l'atteste la fronde des brasseurs de saké de 1881-1885 ${ }^{81}$. Il adresse la même critique à la patente, qui nécessite des registres et des contrôleurs, source de dépenses inutiles: le montant de l'impôt foncier a contrario est fixé pour plusieurs années, avec le seul inconvénient des années de mauvaise récolte. Cependant, Taguchi ne fournit aucun chiffre pour étayer cette affirmation.

73 Son opposition à la révision du prix des terres est aussi fondée sur le coût de tels travaux. À partir de 1891, la hausse du prix a pour corollaire le recul de la revendication de la baisse de l'impôt foncier, remplacée par celle de la révision du prix des terres à laquelle Taguchi s'opposa aussi. Il mettait en cause le coût énorme des enquêtes (plus de trente millions de yen), leur efficacité (des plus réduites) et l'équité fiscale de la réforme (peu évidente). Selon lui, il valait mieux s'en tenir aux principes en vigueur, qui permettaient un prélèvement peu coûteux. Pour Taguchi, cette révision 
n'était pas le moyen adéquat. En effet, le prix du riz à l'époque n'était pas plus élevé qu'au temps de la promulgation de la réforme de l'impôt foncier. Le prix des terres calculé sur cette base ne pouvait qu'entraîner leur hausse, d'autant que les prix du marché étaient plus élevés que ceux officiellement publiés. En outre, il n'y avait ni critères ni autorités capables de décider. À ses yeux, il résulterait de tout cela des coûts énormes pour un résultat mitigés2.

La crise financière consécutive à la guerre avec la Chine lui permit d'affiner son analyse et ses propositions. Taguchi explique alors que le gouvernement ne doit pas se contenter d'une simple augmentation de l'impôt foncier, mais qu'il doit s'appuyer sur les forces vives du pays, en premier lieu par une réforme des finances publiques, qui implique la suppression totale des mauvais impôts, et une hausse de l'impôt foncier ${ }^{83}$. En outre, force est de constater que la part de l'impôt foncier dans les recettes est alors en diminution par rapport à 1874 .

Taguchi se démarque donc nettement des dirigeants du Parti libéral et de ses associations, qui se limitent à un slogan sans expliquer s'ils comptent pallier cette baisse de recettes par une baisse équivalente des dépenses, par l'obtention d'autres recettes (augmentation d'autres taxes, recours à l'emprunt) ou grâce à d'autres solutions. Toutefois sa critique laisse le lecteur perplexe. En effet, il procède plus par affirmations péremptoires que par une description étayée des critères de calcul de la valeur des terres. Considère-t-il que l'impôt foncier porte sur la rente foncière en raison du capital-terre (rishi)? Aucun des textes consultés ne comporte une telle démonstration.

\section{Arguments moraux}

76 Taguchi ne circonscrit pas ses critiques au seul domaine technique. Comme ses modèles anglais, il se réclame aussi de l'efficacité et de la justice sociale. Ainsi en octobre 1896, alors membre du Parti du progrès ${ }^{84}$ (Shinpo-tō 進步党), il récuse vivement l'argument des effets d'une baisse du taux de l'impôt foncier, car celle-ci n'a aucune relation avec le cours du riz. Il explique qu'une diminution de 0,5\% n'a aucun sens, que le cours du riz soit de 4 yen ou de 11 yen, et qu'il faut donc au contraire augmenter l'impôt foncier ${ }^{85}$. Par ailleurs, il écrit en 1893 qu'une baisse de cet impôt aggraverait la concentration des terres entre les mains des plus gros propriétaires au détriment des petits exploitants ${ }^{86}$. En outre, les métayers ne tireraient aucun profit d'une baisse. Sa polémique avec Tani Kanjō 谷干城 (1837-1911) à ce sujet est révélatrice. Tani Kanjō, ancien général et agrarien, originaire du très rural département de Kōchi, fut l'adversaire le plus résolu d'une hausse de l'impôt foncier, au nom des petits exploitants. Il fut donc aussi l'adversaire le plus déterminé de Taguchi.

Taguchi affiche son optimisme sur le sort des exploitants en faire-valoir direct, qui ne pouvaient que bénéficier de la hausse du prix du riz. En effet, la définition par Tani de la propriété foncière et de ses limites ne concernait pas la rente foncière, et donc cette petite propriété paysanne n'était en aucun cas menacée. De toute façon, il est vain d'empêcher la concentration des terres qui est inéluctable.

Taguchi estime que d'autres taxes sont beaucoup plus néfastes que l'impôt foncier, qu'il oppose notamment aux différents types d'impôts locaux institués en 1878 dans le cadre de la législation sur les collectivités locales: taxe d'habitation (en 1887, 260000 
personnes furent incapables de la payer), patente ${ }^{87}$ et taxes diverses. Dans les taxes nationales, il cite la taxe sur les produits d'exportation (yushutsu-zei).

Mais c'est la taxe d'habitation qui est, à ses yeux, la plus néfaste. Dans un article publié le 28 avril 1894, «La nocivité de la taxe d'habitation " $^{88}$ (Kosū-wari no heigai 戸数割の 弊害), il explique que 170000 foyers n'ont pas acquitté cette taxe contre 263 individus qui n'auraient pas payé l'impôt foncier. La carte des sanctions montre de fortes inégalités. A ce moment, le thème de la révision du prix des terres bat son plein. Après la présentation de chiffres prouvant l'inégalité entre les deux impôts, Taguchi conclut : "Ainsi la suppression de la taxe d'habitation profiterait à plus de six millions de foyers, la révision du prix des terres à trente mille seulement !»

Si nuancé dans ses analyses, il semble ici ignorer la coupure géographique qui marque le mouvement pour la réduction de l'impôt foncier : l'opposition entre l'ouest (où la réduction est fondée sur la révision du prix des terres) et l'est (où la réduction est fondée sur la révision du taux de l'impôt). Ces deux factions, nonobstant l'affiliation politique identique de leurs membres, se combattirent, révélant un véritable antagonisme régional entre les propriétaires fonciers de l'ouest et de l'est du Japon, dû en partie aux bouleversements dans les capacités de productions locales survenus depuis la Restauration de Meiji et aux conséquences sur les prix de la mise en place des chemins de fer ${ }^{89}$. En fait, cette coupure apparut dans 1884-1885, dès la déflation jugulée.

81 Par ailleurs, Taguchi affirme que le montant de la patente est inégal d'un département à l'autre et que, « fondée sur le chiffre d'affaires, elle plonge les entrepreneurs dans le plus grand désarroi $»^{90}$. En effet, l'application des méthodes de levée varie d'un département à l'autre, de nombreuses personnes sont acculées à la faillite, et l'imposition des pauvres est lourde tandis que celle des riches est faible. Ces trois impôts locaux ne peuvent être confiés aux conseils généraux, ils doivent être totalement supprimés, l'État prenant en charge certaines dépenses.

82 Taguchi loue le conseil général de Tōkyō qui, avec l'accord des ministères des Finances et de l'Intérieur, a modifié l'application de la législation ${ }^{91}$, introduisant une taxe (kaya$z e i$ 家屋税) estimée plus rentable et plus équitable que la taxe d'habitation. Grâce à elle, la charge fiscale des plus pauvres aurait été réduite d'un tiers.

Il ajoute que d'autres impôts comme les droits de douane, la taxe sur les alcools et le tabac ne sont pas perçus avec équité, à la différence de l'impôt foncier qui ne souffre d'aucune exemption, quelle que soit la marchandise produite ou l'activité de l'individu sur son lieu de résidence. Par conséquent, avec l'impôt foncier, ceux qui produisent beaucoup paient beaucoup, en revanche ceux qui produisent peu paient peu.

Selon Taguchi, cet impôt, acquitté par le possesseur de biens comme par l'ouvrier, est équitable et juste, à la différence de ce qui se passait à l'époque des Tokugawa, où l'impôt pesait sur les paysans alors que les marchands en étaient exemptés: les campagnes payaient l'impôt et les villes ne le payaient pas. Ce système n'était pas éloigné du système actuel. En conclusion, Taguchi propose pour les cinq ans à venir une baisse de l'ensemble des impôts et une hausse de l'impôt foncier. Ces arguments sont répétés en 1894, à la veille de la guerre sino-japonaise dans un "Avis sur les finances publiques de l'Empire $»^{92}$ (Teikoku zaisei iken 帝国財政意見). Taguchi y défend l'urgence politique d'une profonde réforme des finances publiques (zaisei no kakushin). L'ensemble des charges devait être payé par les propriétaires fonciers ne tirant pas leur revenu d'un travail direct. En rupture avec ses amis politiques, il soutint le gouvernement dans son refus de baisser l'impôt foncier au nom de l'égalité fiscale, 
décision accompagnée, entre autres, d'une réduction drastique des crédits de l'armée de terre et de la marine.

Ouchi, dans sa préface du volume 6 des Euvres complètes, affirme que Taguchi, convaincu de l'essor illimité de l'industrie et du commerce, aurait repris les exigences concrètes des secteurs commerciaux et manufacturiers de l'époque, mais il n'eut pourtant de cesse de dénoncer la collusion entre la bureaucratie et les zaibatsu.

\section{Arguments politiques}

Taguchi souligne que les propriétaires fonciers dominent les assemblées locales, conseils municipaux et conseils généraux, puis à partir de 1890 le Parlement où ils défendent leurs intérêts, mais il reste vague sur le détail de la composition exacte de la Chambre des représentants ${ }^{93}$. Il dénonce la collusion du gouvernement et des propriétaires, fondée sur une relation de protection, comme le prouve, entre autres, la mise en place d'une législation et d'une administration de l'agriculture, et donc d'une politique agricole. Il cite les exemples de la création du ministère de l'Agriculture et du Commerce (Nōshōmu-shō 農商務省) en 1885, de la politique des prix et donc du soutien à l'agriculture, du crédit, de l'enseignement, de la diffusion des techniques, des associations professionnelles encouragées ou non par le gouvernement (les rōnō 老農 ${ }^{94}$ - mot-à-mot "paysans âgés »), sans oublier la diversité des discours officiels sur les paysans et leurs supposées vertus. La polémique prit une nouvelle tournure après la crise financière due à la guerre sino-japonaise.

En vérité, la question de la présence des grands propriétaires fonciers au Parlement à l'ère Meiji est une affaire complexe, d'autant que la notion de "propriétaire foncier " est une catégorie fiscale, et non sociale. Elle ne signifie donc pas forcément agriculteur exploitant. Le Parlement impérial de 1890, élu au suffrage censitaire, avec un droit de vote et d'éligibilité fixé à 15 yen, ne concernait que $1,14 \%$ de la population japonaise. $\mathrm{Au}$ cours des six premières législatures (1890-1902), la principale revendication des propriétaires fonciers porta sur la baisse de l'impôt foncier et les réductions budgétaires. Les partis politiques s'affrontèrent vigoureusement avec le gouvernement sur cette question.

En 1890, 252 élus siègent à la Chambre des pairs et 300 à la Chambre des représentants $\mathrm{s}^{95}$. Lors de la première législature, 88 représentants propriétaires fonciers (29\%) payaient plus de 90 yen d'impôt foncier; lors de la deuxième, ils étaient 95 (32\%). Lors des six premières législatures, environ une centaine d'élus (soit un tiers) payaient plus de 90 yen d'impôt foncier. Les élus payant entre 30 et 90 yen d'impôt foncier (exploitants directs inclus) - les plus nombreux - furent au fil des ans fortement impliqués dans les problèmes de la propriété foncière. En 1898 et 1899, Taguchi préconisa une révision du mode de scrutin qui passait par l'extension du suffrage à la population citadine $^{96}$ pour remédier au défaut d'un Parlement dominé par les propriétaires fonciers.

89 À la Chambre des pairs, le poids des plus grands propriétaires fonciers, désignés par le gouvernement, membres de l'aristocratie ou élus par des notables, était plus grand ${ }^{97}$. Par ailleurs, dans les conseils d'arrondissement (gunkai 郡会) siégeaient les propriétaires fonciers de terres d'une valeur égale ou supérieure à 10000 yen.

90 La polémique se poursuit toujours sur la nature des rapports entre l'Etat de Meiji et les propriétaires fonciers. Exista-t-il entre eux un antagonisme caractérisé ou des rapports 
de bienveillance? Le gouvernement prit-il son parti de tensions, voire de vives oppositions, pouvant conduire à la dissolution d'assemblées élues comme les conseils généraux?

91 Taguchi, proche du Parti constitutionnaliste de la réforme, formation libérale dont la base politique repose sur les classes moyennes de Tōkyō et sa région, se démarque nettement du Parti libéral d'Itagaki Taisuke 板坦退助 (1836-1919) à l'assise largement rurale, fortement implanté à Kōchi, profondément protectionniste, en contradiction avec les fondements des principes libéraux.

Les causes directes de cette hostilité résident, selon nous, dans deux faits :

- Taguchi est avant tout un homme et un élu de la capitale, il n'a donc aucune clientèle rurale à satisfaire. À partir de son entrée au conseil d'arrondissement d'Ushigome, puis au conseil général de Tōkyō, il se base sur son expérience d'élu local.

- Taguchi est un libéral, partisan de la puissance industrielle du Japon. A l'instar des penseurs anglais, sa référence idéologique majeure, il accorde une grande importance au commerce extérieur, à la libéralisation des échanges, à l'industrie et aux services, porteurs d'une plus grande valeur ajoutée que les produits agricoles.

\section{Les propriétaires fonciers non exploitants directs et le métayage}

La critique de l'impôt foncier par Taguchi s'étend aux propriétaires, à leur pratique du métayage, ainsi qu'à leur domination des assemblées locales et nationale. La critique de ce système était-elle totalement fondée? Ne souffrait-elle pas de simplifications réductrices ou d'omissions, comme ce fut le cas pour son analyse trop globale de la campagne menée pour la réduction du prix du riz et la révision du prix des terres?

Nous n'aborderons pas ici l'historiographie abondante et polémique au sujet de la rente foncière, des rapports des propriétaires avec leurs métayers, ou de leur rôle dans l'innovation technologique et la hausse quantitative et qualitative de la production agricole.

La critique de Taguchi vise essentiellement les propriétaires fonciers (jinushi) en tant que tels, et non les exploitants en faire-valoir direct (tezukuri jinushi 手作地主), ni les gros paysans (gōnō 豪農), possesseurs d'exploitations plus vastes, cultivées avec l'aide d'ouvriers agricoles logés et nourris. Ceux-ci tirent en effet l'essentiel de leur revenu de leur exploitation et non d'une rente ${ }^{98}$, et c'est un point que Taguchi ne développe pas. Sa défense de l'impôt foncier le conduit à une dénonciation virulente du système de métayage, assimilé à une exploitation éhontée, faisant fi des aléas de la conjoncture et globalement profitable aux propriétaires.

Dans son «Explication sur la rente foncière " ${ }^{99}$ (Kosakuryō no kai 小作料の解), publié le $1^{\mathrm{er}}$ avril $1891^{100}$, Taguchi explique la confusion sémantique qui règne au Japon sur le terme kosakuryō, assimilé à l'impôt foncier (chiso). Il y présente les diverses interprétations de la rente foncière, dont celle de Ricardo, liée à une augmentation de la demande qui entraîne la mise en culture de terres moins fertiles.

Dans un autre texte, «De l'impôt foncier» (Chiso-ron 地租論), publié le 23 octobre $1897^{101}$, Taguchi écrit que l'impôt foncier n'a aucune incidence sur le sort des métayers et des locataires de terrains et que, comme la rente (chiryō 地料) n'est pas le résultat des efforts accumulés du propriétaire foncier, elle est facteur de progrès social. 
Récemment, par exemple, dans le département de Tōkyō, la rente a enregistré une forte augmentation, qui n'est pas le résultat de l'amélioration des terres par leurs propriétaires, mais le résultat de l'augmentation de la population et de la prospérité du commerce. Quant aux propriétaires fonciers, qui n'ont pas même déboursé un sen, ils monopolisent les effets du progrès social en augmentant leurs rentes : leurs profits sont donc injustes. Taguchi semble nier le rôle des efforts entrepris par les propriétaires dans la hausse de leurs profits, qu'il attribue à la seule augmentation de la demande. Jusqu'à la fin de sa vie, il n'aura de cesse de répéter que la rente foncière (chidai 地代) est un revenu non issu d'un travail direct (furō shotoku 不労所得). La taxation d'un tel revenu devrait permettre d'éliminer l'injustice que constitue un Parlement dominé par les propriétaires fonciers.

98 A la fin de sa vie, Taguchi abandonne l'analyse rigoureuse pour se livrer à une attaque virulente contre les propriétaires fonciers. Dans une conférence tenue en février $1903^{102}$, «Finances publiques et économie» (Zaisei to keizai 財政と経済), les titres des quatre chapitres consacrés à ce problème sont: «Le despotisme des propriétaires fonciers", "Des moyens de se prémunir contre les propriétaires fonciers", "Les partisans de la réduction de l'impôt foncier et les socialistes » et «Les propriétaires fonciers mènent une vie d'oisiveté ».

Sa vision des propriétaires fonciers est réductrice. Il les accuse d'exploiter les paysans et de dilapider les biens de la production nationale. La situation des paysans serait pire qu'à l'époque des Tokugawa, écrit-il, sans pour autant préciser sur quels critères. Il accuse aussi les propriétaires fonciers de profiter de leur pouvoir au Parlement (qu'il compare à la chambre des Lords) pour bénéficier de la protection de l'État, en particulier d'exemptions fiscales, sans pour autant que leurs métayers en profitent aussi, y compris en cas de catastrophe naturelle. Par ailleurs, les hausses de prix leur sont favorables, et une baisse de l'impôt foncier serait infiniment moins profitable aux métayers qu'aux gros propriétaires fonciers, leurs oppresseurs. La nouveauté que constituent les baux de métayage et leurs clauses aggrave cette tyrannie. Le seul remède est donc une hausse de l'impôt foncier. En vérité, ce texte tient plus du pamphlet que de l'analyse et s'inscrit dans un contexte de développement des conflits entre métayers et propriétaires fonciers, et d'essor de l'industrie lourde. Taguchi ignore les progrès de l'agriculture, en particulier de la hausse des rendements correspondant à l'accroissement de la population.

Les critiques, parfois féroces, de Taguchi, perdent de leur force et de leur pertinence en raison de leurs excès et d'omissions. Ainsi, dans l'ensemble de son œuvre, Taguchi ne semble nullement mentionner les huit principaux types de contrats de métayage en vigueur à l'ère $\mathrm{Meiji}^{103}$. Il ne prend pas en compte, à partir des années 1880 , l'imbrication des prix du riz, du coût des investissements, des salaires des ouvriers agricoles et de la stabilité virtuelle de la charge fiscale. Il passe rapidement sur les différences régionales, parfois fortes, en particulier entre le Kansai et le Tōhoku. De même, il ne nuance nullement le phénomène de la cession des terres aux propriétaires fonciers, dont l'ampleur et le rythme connurent aussi de fortes variantes locales. Il semble récuser le rôle conjoint des propriétaires fonciers et du nouvel État, notamment dans l'innovation agricole, la hausse des rendements, la mise en place d'un enseignement technique. Au contraire, il accuse les propriétaires de n'être soucieux que de leurs intérêts égoïstes. Les différents courants de l'historiographie marxiste reprirent grosso modo cette analyse. 
101 Sa vision dualiste, purement économiste, des rapports entre les propriétaires fonciers et leurs métayers l'empêche de prendre en compte la spécificité des relations humaines entre les deux parties. Des historiens, comme Ann Waswo, ont souligné que nombre de propriétaires fonciers, par volonté ou par contrainte implicite, prenaient en compte les difficultés de leurs métayers dues à des mauvaises récoltes ou des catastrophes naturelles. La situation se dégrada dès lors que les propriétaires quittèrent leurs villages pour la ville. De plus jeunes historiens comme Shōji Shunsaku 庄司 俊作, prenant l'exemple du département de Hyōgo des années 30 de l'ère Meiji jusqu'au milieu de l'ère Taishō (1912-1926), tout en reconnaissant la sujétion à laquelle les métayers étaient soumis, emploient l'expression «propriétaires fonciers bienveillants » ${ }^{104}$ (onjō jinushi 温情地主).

102 En vérité, nombre de propriétaires firent profiter leurs métayers de leurs bénéfices. A mains égards, la maison Honma 本間, de la plaine côtière du Shōnai dans le département de Yamagata, est à la fois emblématique et exceptionnelle. Jusqu'à la réforme agraire ordonnée par les Américains en décembre 1945, les Honma étaient la plus importante maison de propriétaires fonciers de tout le Japon avec plus de 1500 hectares de terres. Si leurs métayers versaient une rente plus élevée, ils bénéficiaient d'une plus grande sécurité dans le long terme. Par ailleurs, les grands propriétaires fonciers comme les Honma pouvaient plus facilement se lancer dans des investissements coûteux et affronter les risques liés aux mauvaises récoltes ${ }^{105}$, à une époque où les banques spécialisées dans le crédit aux exploitants agricoles étaient encore peu importantes et les coopératives absentes. Sous la direction des Honma, le Shōnai devint la région du Tōhoku - à récolte unique - aux plus hauts rendements.

\section{Les sources}

L'analyse de Taguchi est redevable à la fois à Smith, Ricardo et Richard Cobden. Il reprend en effet les quatre maximes de Smith sur le bon impôt, qui se résument en quatre mots : équité, commodité, certitude, économie de coûts.

104 Tout en rappelant régulièrement ces principes dans son œuvre, Taguchi se fait aussi le disciple de Ricardo, dont il adopte la rhétorique sur le métayage : « La rente est cette part du produit de la terre payée au propriétaire pour l'usage des facultés productives et indestructibles du sol ${ }^{106}$. Il s'agit donc bien pour lui d'un prélèvement sur le revenu de l'exploitant agricole ${ }^{107}$. L'influence de Ricardo est également patente dans ses "Explications sur la rente foncière ». Comme l'explique François Mahieu, pour ce dernier, « la rente foncière est fonction du degré de fertilité des terres. Il en déduit la loi de la rente différentielle : l'excédent de profit est réalisé dans les exploitations où les conditions de production sont les plus favorables. Il se démarque ainsi de Smith qui affirme que l'impôt foncier est déduit de la rente, comme la plupart des impôts, et qu'il est répercuté par une hausse des prix qui pèse sur le consommateur ${ }^{108}$ ».

Par ailleurs, Taguchi puise son hostilité aux propriétaires fonciers chez Cobden qui, mêlant arguments économiques et moraux, dénonça la responsabilité de l'aristocratie foncière anglaise dans la cherté artificielle du prix du pain, grâce aux Corn Laws ${ }^{109}$, et plaida pour l'amélioration du sort des plus défavorisés. Dans un contexte fort différent, puisque le Japon de Meiji n'a pas de propriétaires fonciers (landlords) comparables à ceux de l'Angleterre, la conférence de 1903, véritable brûlot, est aussi véhémente que 
les pamphlets de Cobden, qui n'hésitait pas à employer des mots comme " poignée de tricheurs, de vampires, de bandits puants et sensuels $»^{110}$.

\section{Conclusion}

L'originalité des positions de Taguchi sur les seuls deux thèmes évoqués dans cet article ne pouvait manquer de l'isoler de nombre de ses contemporains, notamment de Fukuzawa Yukichi. Pour ce dernier en effet, le libre-échange était prématuré, car il représentait une source de marasme et de dépendance pour les pays non développés. C'était à ses yeux un des dangers potentiels les plus nocifs pour le Japon ${ }^{111}$. D'autre part, si Taguchi et Fukuzawa s'opposèrent l'un et l'autre à toute baisse de l'impôt foncier, la motivation du second reposait uniquement sur des raisons d'ordre social. En juin 1892, dans un article intitulé "De l'impôt foncier » (Chiso-ron 地租論), il s'opposait à la baisse de celui-ci, qui ne pouvait qu'encourager la concentration des terres au détriment de la moyenne paysannerie, la réforme de l'impôt, officielle en $1872^{112}$, ayant permis la simplification des procédures de transaction.

107 Avec courage et détermination, malgré certaines contradictions, Taguchi se montra inflexible dans ses opinions. Son nationalisme tardif semble tenir moins d'un revirement que d'une inquiétude face à l'expansionnisme russe, comme le prouve son refus catégorique de l'annexion de la Corée, pacifisme conforme à son libéralisme. Sa "République du commerce", panacée de la paix et de la prospérité universelles, ignorant les frontières, ne pouvait relever que de l'utopie dans le contexte économique, politique et idéologique de l'époque. C'est dans cette perspective que Taguchi contribua inlassablement à la diffusion des grands textes des libéraux britanniques que furent Smith et Ricardo.

Malgré les réserves qui peuvent être émises à son encontre, son analyse des propriétaires et de la fiscalité foncière, en rupture avec ses contemporains, fut la plus élaborée de son époque, et elle s'explique sans doute par ses origines sociogéographiques et ses références idéologiques. Taguchi eut des épigones, dans les divers courants marxistes japonais paradoxalement, séduits, entre autres, par sa filiation avec Ricardo. Que trois des huit volumes de ses œuvres complètes aient été introduits par des marxistes le prouve éloquemment ! Par ailleurs, des libéraux comme Kawai Eijirō 河合栄次郎 (1891-1944) le considèrent comme un dirigeant d'opinion, malgré son isolement ${ }^{113}$ dû à l'incapacité du libéralisme à pénétrer l'ensemble des élites. Aussi Taguchi représente-t-il une véritable rupture idéologique par rapport à ses prédécesseurs ou ses contemporains, rupture rendue possible dans le contexte d'ouverture sur un Occident dont le Japon humilié cherchait les recettes.

Toutefois, en dépit de ses activités, de ses talents multiples et de ses réseaux, la fermeté inébranlable de Taguchi lui ferma la carrière politique. En effet, à deux reprises, en désaccord avec sa formation politique, il rejoignit les non-inscrits. Ses thèses sur le libre-échange et son hostilité aux propriétaires fonciers barrèrent la route de tout gouvernement à l'élu du centre de Tōkyō, défenseur intransigeant des intérêts fiscaux de la population urbaine, dans un Japon très rural, où les propriétaires fonciers sont majoritaires à la Chambre des représentants et où les très grands propriétaires fonciers, anciens hauts fonctionnaires et hauts gradés, dominent la Chambre des pairs et les gouvernements. Pour les mêmes raisons, son influence fut des plus maigres dans les milieux économiques protégés par le pouvoir politique et administratif, d'autant 
que les grandes puissances économiques occidentales pratiquaient une politique protectionniste. Malgré son influence inexistante dans les décisions politiques et économiques de son époque, il demeure une des figures marquantes et originales de l'ère Meiji, sans compter qu'avec sa "République du commerce ", il apparaît encore aujourd'hui comme un précurseur.

\section{NOTES}

1. En France, le métayage " associait étroitement le propriétaire à un exploitant pauvre ", alors que le fermage "remettait la terre pour un délai supérieur à six ans à un chef d'entreprise indépendant, disposant souvent de capitaux" (Pierre Barral, Les Agrariens français de Méline à Pisani, Cahiers de la fondation nationale des sciences politiques 164, Armand Colin, 1968, p. 28). Nous avons donc retenu le premier terme qui nous semble plus approprié dans le cas du Japon de l'époque.

2. Kawai Eijirō zenshū 河合栄次郎全集, vol. 11, Nihon no jiyū shugi no tokushusei 日本の自由主義 の特殊性 (Les spécificités du libéralisme japonais), p. 308-310, Shakai shisō-sha 社会思想社, 1967.

3. Taguchi Chikashi 田口親, Taguchi Ukichi 田口卯吉, Jinbutsu sōsho 人物叢書, 226, Yoshikawa kōbunkan 吉川弘文館, 2000, p. 1.

4. Ibid., p. 30.

5. Grand admirateur de Voltaire, Adam Smith était comme lui un déiste rationaliste. Il est possible que ses conceptions aient influencé Taguchi (Alain Bruno, Adam Smith: vie, œuvres, concepts, Ellipses, p. 11).

6. Smith, contrairement aux idées reçues, était étranger à ce principe. Pour lui, au contraire, l'État devait réglementer le marché et intervenir dans la société (ibid., p. 80-81).

7. Homme d'affaires avisé, puis député, et auteur Des principes de l'économie politique et de l'impôt, dont la première édition fut publiée en 1817.

8. Cobden et ses amis, farouches partisans du libre-échange, fondèrent en 1838 une ligue contre le protectionnisme sur les grains, qui mena un combat national. En 1846, elle parvint à faire voter le libre-échange unilatéral au Parlement. En 1860, Cobden fut le signataire du traité de libreéchange entre la Grande-Bretagne et la France.

9. Bastiat, économiste, auteur des Harmonies économiques, fut le traducteur de Cobden.

10. Société politique créée en 1874 . Elle lança sa revue Ōmei zasshi en 1878, à laquelle participa Taguchi. En 1880, son implantation se limitait aux régions du Kantō et du Tōhoku. Elle revendiquait un millier d'adhérents. Ses membres rejoignirent le Parti constitutionnaliste de la réforme dès sa création en avril 1882. L'Ōmei-sha dut se dissoudre trois mois plus tard, conformément à l'article 8 de l'ordonnance sur le droit de réunion et d'organisation (shūkai jōrei 集会条例) d'avril 1880, qui interdisait toute coalition et communication entre organisations politiques.

11. Baba Keinosuke 馬場啓之助, 《Taguchi Ukichi ron»田口卯吉論 (Sur Taguchi Ukichi), Hitotsubashi ronsō 一橋論叢, vol. 57, $\mathrm{n}^{\circ}$ 4, avril 1967.

12. Smith nuance toutefois son propos sur ce sujet. Il prône une politique protectionniste pour défendre l'industrie "nécessaire à la défense du pays » et les produits nationaux chargés «de quelque impôt dans l'intérieur » (Richesse des nations, livre IV, chapitre 2). 
13. Les deux hommes défendaient la liberté économique, néanmoins des divergences de fond les séparaient, notamment sur les rapports entre l'Etat et l'individu. Voir Sakamoto Shin.ichi 坂本慎 一, «Shibusawa Eiichi to Taguchi Ukichi no tairitsu: Meiji jidai no keizai jiyū shugi o meguru “Bunmei no shōtotsu”》渋沢栄一と田口卯吉の対立明治時代の経済自由主義を巡る「文明の 衝突」 (Les divergences entre Shibusawa Eiichi et Taguchi Ukichi : Le libéralisme économique de l'ère Meiji, «un choc de civilisation»), Keizai-gaku zasshi 経済学雑誌, Ōsaka shiritsu daigaku keizai gakkai 大阪市立大学経済学会, 99/3-4, novembre 1998. Repris en partie dans Shibusawa Eiichi no keisei saimin shisō 渋沢栄一の経世済民思想 (La pensée du bon gouvernement du peuple chez Shibusawa Eiichi), Nihon keizai hyōron-sha 日本経済評論社, 2002, 334 p.

14. Christiane Séguy, Histoire de la presse japonaise, POF, 1993, p. 172.

15. Né à Nagasaki, il fonda le Tōkyō nichinichi shinbun, journal pro-gouvernemental, en 1874. Il fut élu à la Chambre des représentants en 1904. Il fut aussi un des fondateurs du théâtre Kabuki-za de Tōkyō.

16. Taguchi Chikashi, op.cit., p. 89-103.

17. Ariyama Teruo 有山輝雄, «Keizai jânarizumu toshite no Tōkyō keizai zasshi » 済ジャーナリズ ムとしての東京経済䧱誌 (Tōkyō keizai zasshi, journal économique), dans Sugihara Shirō 杉原四 郎 et Okada Kazunobu 岡田和喜 (dir.), Taguchi Ukichi to Tōkyō keizai zasshi 田口卯吉と東京経済䧱 誌 (Taguchi Ukichi et la revue Tōkyō keizai zasshi), Nihon keizai hyōron-sha 日本経済評論社, 1995, p. 327 et 333.

18. Tessa Morris-Suzuki, A History of Japanese Economic Thought, Routledge, Londres, 1991, p. 54-55; Claude Hamon, "Confucius et la règle à calcul ", dans La Nation en marche. Études sur le Japon impérial de Meiji, 1999, p. 91.

19. Né à Okayama, il étudia à Keiō et mena une carrière de journaliste et d'homme politique. Nommé Premier ministre en décembre 1931, il fut assassiné en mai 1932 par des officiers ultranationalistes.

20. Ariyama Teruo, op. cit., p. 327.

21. Thomas Thooke (1774-1858). Financier, économiste et partisan du libre-échange. Avec Ricardo, Malthus et Mill, il participa en 1821 à la fondation du Political Economy Club.

22. Société d'import-export Mitsui fondée en 1876 (voir Dictionnaire Historique du Japon, fasc. XIV, 1988, p. 125).

23. Les premiers exemplaires de La Richesse des nations furent sans doute introduits au Japon à la fin du bakufu.

24. Hane Mikiso, "The sources of English Liberal Concepts in Early Modern Japan », Monumenta Nipponica, vol. xxIV, $\mathrm{n}^{\circ} 4,1969$, p. 265.

25. Voir Mori Hisao 森久男, “Taguchi Ukichi no shokumin-ron» 田口卯吉の殖民論 (Le colonialisme de Taguchi Ukichi), dans Kojima Reiitsu 小島麗逸 (dir.), Nihon teikoku shugi to Higashi Ajia 日本帝国主義と東アジア (L'impérialisme japonais et l'Asie orientale), n²77, Ajia keizai kenkyūjo アジア経済研究所, 1977, p. 45.

26. Ibid, p. 30-32. Adam Smith justifiait cette colonisation antique des « contrées lointaines [...] habitées par des peuples entièrement barbares » (La Richesse des nations, livre IV, chapitre 7 « Des colonies »).

27. L'idée de division n'est pas originale, mais Smith fut le premier à mettre aussi fortement l'accent sur elle. Elle devient pratiquement le seul facteur des progrès économique et technique, investissements inclus (Schumpeter, op. cit., vol. I, p. 266).

28. Il reprenait les idées de Honda Toshiaki 本田利明 (1744-1821), qui préconisait le développement pacifique des territoires actuels de Hokkaidō, Sakhaline et du Kamtchatka pour y installer des comptoirs commerciaux et bloquer la menace russe.

29. Cuvres complètes, vol. 5, p. 466-467.

30. Ibid., p. 546. 
31. Ce traité, signé en février 1876, consacrait la Corée comme un État indépendant, jouissant des mêmes droits que le Japon, le soustrayant ainsi à la suzeraineté chinoise. Il décida de l'échange de représentants diplomatiques au rang de ministres. Le Japon imposait à la Corée un droit d'accès de ses navires dans trois ports, ainsi qu'un statut d'extra-territorialité pour ses résidents. Le Japon appliquait à son voisin la politique dont il était lui-même victime de la part des puissances occidentales et qu'il n'avait cessé de dénoncer.

32. André Fabre, La Grande histoire de la Corée, Favre, 1988, p. 298.

33. Philippe Raynaud et Stéphane Rials (dir.), Dictionnaire de philosophie politique, Puf, 1996, p. 565-567.

34. Les Mémoires historiques de Se-Ma-Ts'ien, trad. d'Edouard Chavannes, Adrien Maisonneuve, 1967, vol. 1, p. 275.

35. Zenshū, vol. 4, p. 95-96.

36. Recueil de 49 articles parus entre mai 1884 et juillet 1888. Voir Zensh̄̄, vol. 3, p. 137-143.

37. Homme politique libéral et journaliste. Il fut député de Mie de 1890 à 1952 . Il fut aussi maire de Tōkyō de 1903 à 1912, et plusieurs fois ministre. Ministre de l'éducation en 1890, dans le premier gouvernement ōkuma, il dut en démissionner à la suite d'un discours en faveur du régime républicain (Dictionnaire historique du Japon, fasc. XVI, p. 150).

38. Union douanière des États allemands réalisée au cours du XIX ${ }^{\mathrm{e}}$ siècle.

39. Zenshū, vol. 3, p. 139-140.

40. Komine Kazuo 小峰和夫, «Taguchi Ukichi no kaita kaihō keizai kokka Nihon no shinro » 田 口卯吉の描いた開放経済国家日本の進路 (Taguchi Ukichi et le chemin vers un État japonais d'économie ouverte), dans Sugihara Shirō et Okada Kazunobu, op. cit., p. 223.

41. Ibid., p. 216.

42. Dans un premier temps admirée, notamment le port de Shanghai, et perçue comme une menace pour le Japon, comme l'atteste un article de 1884 : "La puissance réelle de la Chine » (Shina-koku no jitsuryoku 支那国の実力), dans Zenshū, vol. 5, p. 177-183.

43. Komine Kazuo, op.cit., p. 200-201.

44. Zenshū, vol. 4, p. 95-96.

45. Zenshū, vol. 5, p. 407-414.

46. Taxe en vigueur de la fin du bakufu à 1899. Les autorités procédèrent à sa réduction progressive.

47. «Sozei keigen menjo no hōan" (Proposition de loi relative à une diminution ou une suppression de divers impôts), dans Zenshū 6, p. 233.

48. Voir D.H.J., fasc. xv.

49. Kijima Kumi 木島久実, «Taguchi ni okeru jiyū shugi shisō no tokushitsu to sono tenkai » 田 口卯吉における自由主義思想とその展開 (Spécificités et développement de la pensée libérale de Taguchi), Keizairongaku 経済論学, 99, 1997, p. 14.

50. Zenshū, vol. 3, p. 142.

51. Dans «Jōyaku kaisei » 条約改正, Tōkyō keizai zasshi du 29 mai 1879. Cité par Iwanami shoten kōza Nihon tsūshi, Kindai 2 岩波講座日本通史, 近代 2, 1994, vol. 17, p. 118.

52. Pierre Rosanvallon, Le Libéralisme économique. Histoire de l'idée de marché, Le Seuil, 1989, p. 113-114.

53. Kären Wigen, The Making of a Japanese Periphery 1750-1920, California Univ. Press, p. 216; Carol Gluck, Japan's Modern Myths. Ideology in the Late Meiji Period, Princeton Univ. Press, p. 38.

54. Honjō Eijirō 本庄栄治郎, «Nihon keizai shisō-shi»日本経済思想史 (Histoire de la pensée économique japonaise), dans Honjō Eijirō zenshū 本庄栄治郎全集 , vol. 2, Seibun-dō 清文堂, 1971, p. 76-77.

55. Sheldon Charles David, The Rise of the Merchant Class in Tokugawa Japan, 1600-1868, New-York, Russel and Russel, 1973, p. 137.

56. Honjō Eijirō, op.cit., p. 77. 
57. Ibid., p. 77-78.

58. Frédéric Teulon, Vocabulaire économique, «Que-sais-je ?», n 2624, Puf, 1996, p. 76.

59. Richesse des nations, livre IV, chap. 2.

60. Alain Bruno, op.cit., p. 82.

61. Livre IV, "Des systèmes d'économie politique », chapitre 3, « Des entraves extraordinaires apportées à l'importation des pays avec lesquels on suppose la balance du commerce défavorable", section 2, "Où l'absurdité des règlements de commerce est démontrée après d'autres principes », [vol.2, p. 80-93].

62. Livre III, "De la marche différente des progrès de l'opulence chez différentes nations", chapitre 4, "Comment le commerce des villes a contribué à l'amélioration des campagnes », p. 514.

63. Pierre Rosanvallon, op.cit., p. 94.

64. Alain Bruno, op.cit., p. 64.

65. Livre V, «Des dépenses à la charge du souverain ou de la République », section 1, "Des dépenses qu'exige la défense commune ».

66. Christian Schmidt, Penser la guerre, penser l'économie, Odile Jacob, 1991, p. 77.

67. Sur 343 articles recensés, 196 (57 \%) portent sur les questions fiscales. D'après Sugihara Shirō et Okada Kazuyoshi, op.cit., p. 117-122.

68. Zenshū, vol. 6, p. 114-126.

69. «Zaisei to keizai » (Finances publiques et économie), Zenshū 6, p. 5 et 71-85.

70. Parti conservateur appelé aussi Seiyūkai (Association des amis du gouvernement constitutionnel), créé en 1900. Voir Dictionnaire historique du Japon, fasc. XVII, 1991, p. 10.

71. Takayose Shōzō 高寄昇三, Meiji chihō zaiseishi 明治地方財政史 (Histoire des finances locales de Meiji), vol. 2 ; Sanshinpō-ki no chihō zaisei 三新法期の地方財政 (Les finances locales à l'époque des « Trois nouvelles lois »), Keisō shobō 勁草書房, 2002, p. 196.

72. «Sozei keigen menjo no hōan ", Zenshū 6, p. 232-234. À Tōkyō, le cours du riz servant pour l'impôt foncier était de 5,20 yen.

73. Zensh $\bar{u}$, vol. 6 , «Le décret $n^{\circ} 25$ du ministère des Affaires suprêmes " (Dajōkan 25gō no ofukoku 太政官25号の御布告), p. 95-97.

74. « Sozei keigen menjo no hōan », Zenshū 6, p. 232-234.

75. Kudō Eiichi 工藤英一, « Meiji chūki ni okeru chiso zōchō-ron. Taguchi Ukichi o chūshin ni » 明治中期における地租増徵論 一田口卯吉を中心に (Les débats sur la hausse de l'impôt foncier au milieu de l'ère Meiji. Autour de Taguchi Ukichi), Meiji gakuin ronsōo 明治学院論叢, XXXII-2, 1954, p. 49-56 et 57-58.

76. Kudō Eiichi, op. cit., p. 57-58.

77. « De l'impôt foncier» (Chisoron), T.K.Z. n 899, 23 octobre 1897, Zenshū 6, p. 402.

78. Zenshū, vol. 4, p. 154-164.

79. «Des moyens d'une amélioration de la conjoncture commerciale par une baisse des impôts et une réforme de leur prélèvement » (Sozei o genji sono chōshū o aratamete motte shōkyō o kyūjisuru no hōhō ronzu), T.K.Z. $\mathrm{n}^{\circ}$ 197, 19 janvier 1884, Zenshū 6, p. 162-177.

80. «Sozei-ron », octobre 1880, Zenshū vol. 6, p. 114-126.

81. Pascal Hurth, «L'assemblée des brasseurs de saké », Cipango, $n^{\circ} 9$, automne 2002.

82. Kudō Eiichi, op.cit. p. 59.

83. Ibid., p. 61.

84. Ce parti combattit la décision gouvernementale de hausse de l'impôt foncier de 1898.

85. Kudō Eiichi, op.cit. p. 62. Voir aussi Zenshū, vol.6, «Des finances publiques» (Zaisei seiri ni kanshite 財政整理に関して), p. 369-371. 
86. «La baisse de l'impôt foncier profite à de nombreux paysans riches et aux pairs " (Chiso keigen wa ōku gōnō oyobi kazoku o ri-su 地租軽減は多く豪農及び華族を利す), Zenshū, vol. 6, p. 312-313, 2 décembre 1893.

87. Zenshū, vol. 6, p. 326-327, T.K.Z, n ${ }^{\circ} 720$ du 7 avril 1894.

88. Zenshū, vol. 6, p. 331-335.

89. Nakamura Masanori 中村正則, “Chiso zōcho to chika shūsei» 地租増徽と地価修正 (La hausse de l'impôt foncier et la révision du prix des terres), Meiji zaiseishi geppō 明治財政史月報 (Bulletin édité à l'occasion de la parution de Histoire des finances publiques de Meiji), $\mathrm{n}^{\circ} 5$, octobre 1971.

90. «Sozei keigen menjo no hōan ", p. 234. En effet, la répartition per capita de la patente en 1888 est tout à fait différente d'un département à l'autre : 11,12 yen à Tōkyō, 16,38 à Kyōto, 3,41 à Kagoshima, d'après Takayose Shōzō, op.cit., p. 198.

91. «Tōkyō shimin no kōfuku » 東京市民の幸福 (Le bonheur des citoyens de Tōkyō), Zenshū, vol. 6, mai 1894, p. 335-337 ; Takayose Shōzō, op.cit., p. 169.

92. Zenshū, vol. 6, préface, p. 2.

93. En fait, les petits et moyens propriétaires composaient la majorité de la Chambre des représentants, et les grands propriétaires la majorité de la Chambre des pairs, en raison du système électoral propre à cette dernière.

94. Exploitants renommés pour leurs compétences, leur expérience et leur rôle de vecteurs dans l'innovation agricole. Le gouvernement de Meiji les encouragea pour la diffusion de l'innovation. Ils jouent un peu le rôle des comices agricoles.

95. R. H. P. Mason, Japan's First General Election 1890, Cambridge Univ. Press, 1969, p. 1.

96. «Il faut réviser la loi électorale » (Senkyohō kaisei sazeru bekarazaru), T. K. Z., nº 914, 12 février 1898, Zenshū 5, p. 405-407 ; « L'esprit de la révision de la loi électorale » (Senkyohō kaisei no seishin), T. K. Z., nº 1002, 28 octobre 1899, Zenshū 5, p. 443-444.

97. Araki Moriaki 安良城盛昭, «Daiichi gikai ni okeru jinushi giin no dōkō»一議会における地 主議員の動向 (Les orientations des élus propriétaires fonciers à la première législature du Parlement), Shakai kagaku kenkyu 社会科学研究, XVI-1, 1965 [6], p. 1-2.

98. Dore Ronald P., « The Meiji Landlord: Good or Bad?», The Journal of Asian Studies, XVIII-3, mai 1959, p. 350.

99. Zenshū, vol. 3, p. 278-279, T.K.Z., nº 556.

100. La première enquête sur les pratiques de métayage ne fut menée qu'en 1888 (voir Ann Waswo, Japanese Landlords, op. cit., p. 23).

101. Zenshū, vol. 6, p. 402-404 (cité par Kudō, op. cit., p. 62-63).

102. Zenshū, vol. 6, p. 5 et 71-85.

103. Ann Waswo, Japanese Landlords, op. cit., p. 23-26

104. Shōji Shunsaku 庄司俊作, « Les propriétaires fonciers bienveillants » (Onjō jinushi-ron 温情 地主論), in Nakamura Masanori 中村正則 (éd.), Kingendai Nihon no shinshiten 近現代日本の新視 点 (Nouveaux points de vue sur le Japon contemporain), Yoshikawa kōbunkan, 2000. Mais aussi Kindai Nihon nōson shakai no tenkai. Kokka to nōson 近代日本農村社会の展開 一 国家と農村 (Le développement de la société rurale japonaise contemporaine. L'État et le village), Mineruva shobō ミネルヴァ書房, 1992 ; et “"Onjōteki” kosakunin shihai no rekishiteki kaku » 温情的小作 人支配の歴史的格 (Caractéristiques historiques de la domination «bienveillante» sur les métayers), Nihonshi kenkyū 日本史研究, 318, février 1989.

105. Linda L. Johnson, Prosperity and Welfare. The Honma Family and Agricultural Improvement in Meiji Japan, Transactions of the Asiatic Society of Japan, $4^{\circ}$ série, vol. 5, 1990.

106. David Ricardo, Des principes de l'économie politique et de l'impôt, Garnier-Flammarion, 1989, p. 89.

107. Arnaud Combet-Libourel, David Ricardo : vie, cuvres, concepts, p. 31-32.

108. François Mahieu, Ricardo, Economica, 1995, p. 78. 
109. Lois protectionnistes britanniques sur les céréales en vigueur de 1815 à 1846, dénoncées par Ricardo. Elles interdisaient l'importation de grains inférieurs à un prix plancher, elles profitaient essentiellement à l'aristocratie. La cherté du prix du pain, alors nourriture de base des plus pauvres, était un de leurs principaux effets. À partir de 1838, John Bright (1811-1889) et Richard Cobden (1804-1865), industriels du textile libéraux, menèrent une vigoureuse campagne pour leur suppression, qui fut accélérée par la grande famine irlandaise de 1845. Elles furent abolies en 1846.

110. Roland Marx, Histoire de l'Angleterre, Fayard, 1993, p. 367-368.

111. Fujiwara Akio 藤原昭夫, Fukuzawa Yukichi to Nihon keizairon 福沢諭吉と日本経済論 (Les thèses sur l'économie japonaise de Fukuzawa Yukichi), p. 45.

112. Ibid., p. 183.

113. Itō Yahiko 伊藤弥彦, Taguchi Ukichi no seiji shisō田口卯吉の政治思想 (La pensée politique de Taguchi Ukichi), Dōshisha hōgaku 同志社法学, 27/1, 1975, p. 87-88 [note 35, p. 86].

\section{RÉSUMÉS}

Journaliste, historien et homme politique, Taguchi Ukichi s'est fait le chantre du libéralisme à la fin $\mathrm{du} \mathrm{XIX}^{\mathrm{e}}$ siècle en défendant le libre-échange et en s'opposant aux propriétaires fonciers.

Champion of Liberalism at the end of the 19th century, Taguchi Ukichi (journalist, historian and politician) was a staunch advocate of free trade, strongly opposed to landowners.

\section{INDEX}

Keywords : Free Trade, Free Enterprise, Classical School of Economics, Manchester School of Economics, Economics, Taguchi Ukichi (1855-1905)

Mots-clés : libre-échange, libéralisme économique, école classique d'économie politique, École de Manchester, Taguchi Ukichi (1855-1905)

キーワード : jiyū bōeki 自由貿易, keizai jiyū shugi 経済自由主義, kotenha keizaigaku 古典派経 済学, Manchesutā gakuha マンチェスター学派, keizai 経済, Taguchi Ukichi 田口卯吉

(1855-1905), Meiji jidai 明治時代 (1868-1912), seiji keizaigaku 政治経済学

Index chronologique : Meiji (1868-1912)

Thèmes : économie politique 